\title{
Development of FI Catalyst Systems and Their Applications to New Polyolefin-Based Materials
}

\author{
Yasushi Nakayama, Makoto Mitani, Hideki Bando, and Terunori Fujita* \\ R \& D Center, Mitsui Chemicals, Inc.,
}

Received July 17, 2003

\begin{abstract}
The olefin polymerization behavior of bis(phenoxy-imine) group 4 transition metal complexes (named FI Catalysts) is described. In association with methylalumoxane (MAO) or ${ }^{i} \mathrm{Bu}_{3} \mathrm{Al} / \mathrm{Ph}_{3} \mathrm{CB}\left(\mathrm{C}_{6} \mathrm{~F}_{5}\right)_{4}$, FI Catalysts display unique catalytic performance and have created a variety of polyolefin-based materials. For example, FI Catalysts are capable of producing vinyl-terminated low molecular weight polyethylenes $\left(M_{\mathrm{v}}<\right.$ 2000), well-defined multimodal polyethylenes, ultra-high molecular weight amorphous ethylene-propylene copolymers $\left(M_{\mathrm{w}}>10,000,000\right)$, highly syndiotactic polypropylenes with extremely high peak melting temperatures $\left(T_{\mathrm{m}}>150^{\circ} \mathrm{C}\right)$, various block copolymers from ethylene and propylene and stereo- and regio-irregular high molecular weight poly(1-hexene)s. Many of these polymers were unavailable prior to the development of FI Catalysts. Additionally, studies on new cocatalysts for FI Catalysts have resulted in the discovery of FI Catalyst $/ \mathrm{MgCl}_{2}$-based compound systems, which represent the first examples of MAO- and fluoroarylborate-free highly active single-site catalyst systems based on group 4 transition metal complexes.
\end{abstract}

\section{Introduction}

During the past two decades a tremendous amount of academic and industrial research has focused on the discovery and development of high-performance single-site catalyst systems for olefin polymerization. This is because single-site catalyst systems possess well-defined, homogeneous active sites (unlike heterogeneous Ziegler-Natta catalysts) and, therefore, they allow control over stereochemistry, chain transfer reactions and comonomer incorporation.

Advances in the rational design and synthesis of well-defined transition metal complexes, together with the technologically significant discovery of high-performance cocatalysts such as methylalumoxane (MAO), $\mathrm{B}\left(\mathrm{C}_{6} \mathrm{~F}_{5}\right)_{3}$ and $\mathrm{XB}\left(\mathrm{C}_{6} \mathrm{~F}_{5}\right)_{4}\left(\mathrm{X}: \mathrm{Ph}_{3} \mathrm{C}, \mathrm{PhNMe}_{2} \mathrm{H}\right)$ have played a pivotal role in activating and accelerating research aimed at acquiring high-performance single-site catalyst systems.

To date, group 4 metallocene catalysts and constrainedgeometry catalysts (CGC) that are activated with MAO or fluoroarylboron compounds cocatalyst systems have been in the forefront of these developments. ${ }^{1}$ These single-site catalyst systems have created a variety of successful, commercially available high-performance polyolefins with unique microstructures and new or enhanced performance parameters [e.g., linear low-density polyethylenes (LLDPEs), isotactic and syndiotactic polypropylenes (iPPs and SPPs), syndiotactic polystyrenes (sPSs), ethylene-styrene interpolymers (ESIs), cyclic olefin copolymers (COCs) and polyolefinic elastomers].

Because of the need for greater control over polymer properties, in addition to the extension of the generic polyolefinbased products by introducing new monomer combinations, there is presently much interest in the development of new single-site catalyst systems other than group 4 metallocene catalyst systems and CGC systems. These research efforts have resulted in the introduction of a number of new single-site catalyst systems based on both early- and latetransition metal complexes. ${ }^{2-18}$ Examples of these include diimine, ${ }^{4}$ diamide,${ }^{5-7}$ amide-ether,${ }^{8}$ phosphine-imide, ${ }^{9}$ diimine-pyridine ${ }^{10,11}$ and tris(pyrazolyl)borate ${ }^{12}$ chelate ligands. These new single-site catalysts, in association with appropriate cocatalysts, can produce unique polymers (e.g., hyper-branched polymers, polar monomer copolymers and polyolefinic block copolymers from $\alpha$-olefins) that were previously unavailable through other means of polymerization.

Alternatively, the discovery of MAO and fluoroarylboron compounds has spurred research into weakly coordinating anions as potential cocatalysts, leading to the discovery of various cocatalysts such as clay minerals, heteropolyacids and perchlorates in addition to modified MAO and fluoroarylboron-based compounds. ${ }^{19}$ These non-MAO and non-fluoroarylboron-based compounds function as efficient cocatalysts for group 4 metallocene catalysts and CGC, though MAO and fluoroarylboron compounds are still the most effective cocatalysts at the present time.

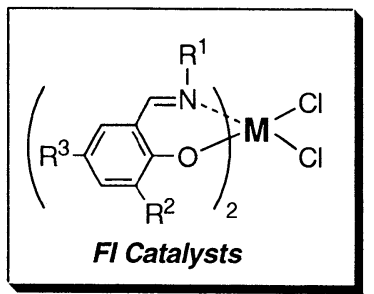

High Performance New Olefin Polymerization Catalysts

M: Ti, Zr, Hf, V, etc. $R^{1}-R^{3}$ : Alkyl, Aryl, Silyl, Heteroatom Containing Groups)

Figure 1. Structure of phenoxy-imine complex catalysts (FI Catalysts).

In our own efforts to develop new high-performance single-site catalyst systems, we have studied well-defined transition metal complexes incorporating non-symmetric bidentate or tridentate ligands with electronically flexible properties. ${ }^{20}$ As a result, we found a number of families of transition metal complexes featuring groups such as phenoxy-imine, ${ }^{20-26}$ pyrrolide-imine, ${ }^{27}$ indolide-imine, ${ }^{28}$ phenoxy-pyridine, ${ }^{29 a}$ phenoxy-ether ${ }^{29 b}$ or phenoxy-imine-pyridine ${ }^{29 c}$ chelate ligands. Some of these complexes can be combined with cocatalysts, such as bis(phenoxy-imine) group 4 
transition metal complexes (named FI Catalysts, Figure 1) with MAO, to form very high-activity catalysts for the polymerization of ethylene.

As disclosed in our patents filed in April 1997 (ethylene, $\alpha$-olefins, and dienes polymerization $)^{21 \text { a }}$ and January 2000 (living polymerization and block copolymer formation), ${ }^{21 \mathrm{~b}}$ and in a series of papers, FI Catalysts in conjunction with MAO or ${ }^{i} \mathrm{Bu}_{3} \mathrm{Al} / \mathrm{Ph}_{3} \mathrm{CB}\left(\mathrm{C}_{6} \mathrm{~F}_{5}\right)_{4}$ cocatalysts display a unique catalysis for olefin polymerization (including living olefin polymerization) and can produce distinctive polymers that are either difficult or impossible to prepare using conventional catalysts. For instance, $\mathrm{Zr}$-FI Catalysts are capable of producing vinyl-terminated low molecular weight PEs $\left(M_{\mathrm{w}}\right.$ 2100), ${ }^{22 \mathrm{i}}$ well-defined bi- and tri-modal PEs, ${ }^{22 \mathrm{~m}}$ ultra-high molecular weight PEs $\left(M_{\mathrm{v}}>5,000,000\right),{ }^{2 \mathrm{~b}}$ amorphous ethylene-propylene copolymers (EPRs, $\left.M_{\mathrm{w}}>10,000,000\right)^{22 \mathrm{j}}$ and high $T_{\mathrm{m}}$ iPPs $\left(T_{\mathrm{m}}>160^{\circ} \mathrm{C}\right)$. In addition, Ti-FI Catalysts can provide high $T_{\mathrm{m}}$ sPPs $\left(T_{\mathrm{m}}>140^{\circ} \mathrm{C}\right),{ }^{23 \mathrm{n}}$ ultra-high molecular weight atactic PPs (aPPs) $\left(M_{\mathrm{w}}>8,000,000\right)^{22 \mathrm{k}}$ and regio- and stereo-irregular high molecular weight poly(higher $\alpha$-olefin)s $\left(M_{\mathrm{w}}>700,000\right){ }^{220}$ Moreover, fluorinated Ti-FI Catalysts are capable of carrying out highly controlled living ethylene polymerization $^{24}$ and highly syndiospecific living propylene polymerization $^{25}$ at the remarkably high temperature of $50^{\circ} \mathrm{C}$, allowing access to both ethylene- and propylene-based block copolymers $^{24 \mathrm{~b}}$ (e.g., PE- $b$-EPR, sPP- $b$-EPR, PE- $b$-EPR- $b$-PE, PE- $b$-EPR- $b$-sPP) in addition to high molecular weight monodisperse PEs $\left(M_{\mathrm{n}}>400,000, M_{\mathrm{w}} / M_{\mathrm{n}}<1.2\right)$ and extremely high $T_{\mathrm{m}} \mathrm{sPPs}\left(T_{\mathrm{m}}>150^{\circ} \mathrm{C}\right)$. Furthermore, the catalytic syntheses of monodisperse PEs and $\mathrm{Zn}$-terminated PEs were achieved by a combination of specifically designed Ti-FI Catalysts with chain transfer agents, ${ }^{24 \mathrm{e}}$ opening up a new methodology for the catalytic production of block copolymers and functional polymers. Therefore, in recent years, there has been increasing interest in the research and development of phenoxy-imine ligated early transition metal complexes for the polymerization of ethylene and/or $\alpha$-olefins using both experimental and theoretical approaches. $^{30-32}$

Now that the high catalytic performance of FI Catalysts with $\mathrm{MAO}$ or ${ }^{i} \mathrm{Bu}_{3} \mathrm{Al} / \mathrm{Ph}_{3} \mathrm{CB}\left(\mathrm{C}_{6} \mathrm{~F}_{5}\right)_{4}$ has been established, we are currently studying new cocatalysts (other than MAO and fluoroarylboron compounds) that are capable of improving catalysis using FI Catalysts. In consequence, we have discovered an $\mathrm{MgCl}_{2}$-based compound that can work as an excellent cocatalyst for FI Catalysts. ${ }^{26}$ We have subsequently developed new highly active, single-site catalyst systems based on FI Catalysts and $\mathrm{MgCl}_{2}$-based compounds, which represent the first examples of $\mathrm{MAO}-$ and fluoroarylboron-free, highly active, single-site catalyst systems with $\mathrm{MgCl}_{2}$-based cocatalysts.

We introduce herein the olefin polymerization behavior of FI Catalysts with MAO and ${ }^{i} \mathrm{Bu}_{3} \mathrm{Al} / \mathrm{Ph}_{3} \mathrm{CB}\left(\mathrm{C}_{6} \mathrm{~F}_{5}\right)_{4}$ cocatalyst systems, and, additionally, we describe the cocatalytic features of $\mathrm{MgCl}_{2}$-based compounds for FI Catalysts.

\section{Search for High-Activity Ethylene Polymerization Catalyst Systems}

\subsection{Catalyst Design Concept}

Historically, the discovery of highly active ethylene polymerization catalyst systems has been the key to creating novel polymers with new or improved material properties, as clearly demonstrated by the discovery of $\mathrm{TiCl}_{4} / \mathrm{R}_{3} \mathrm{Al}, \mathrm{MgCl}_{2}$-supported $\mathrm{TiCl}_{4}$, group 4 metallocene catalyst systems and CGC systems. Bearing this in mind, the purpose of our research has been the discovery of high-activity ethylene polymerization catalyst systems and their application to value-added polyolefin-based materials that are either difficult or impossible to synthesize using conventional catalysts. The targeted polymers include vinyl-terminated low molecular weight polymers, ultra-high molecular weight polymers, high $T_{\mathrm{m}}$ polymers, regio- and stereo-irregular high molecular weight polymers, well-defined multimodal polymers, monodisperse polymers, block copolymers from ethylene and propylene and olefin-polar olefin copolymers.

Scheme 1. General concept of catalyst design

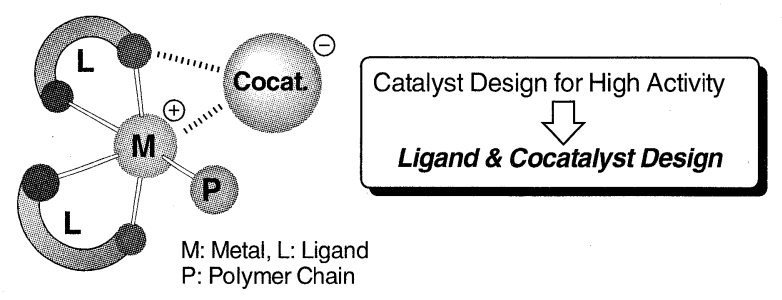

An olefin polymerization catalyst normally consists of a metal, ligand(s), a growing polymer chain, a coordinated olefin and a cocatalyst (Scheme 1). Theoretical calculations using a metallocene catalyst as a model indicate that olefin polymerization is a process involving intense electron exchange between a ligand and a metal. Since all transition metals potentially possess olefin insertion ability, we believe that the combination of a transition metal and electronically flexible ligand(s) can be a highly active olefin polymerization catalyst. Electronically flexible ligands typically possess well-balanced electron-donating and -withdrawing properties (small energy gap between HOMO and LUMO) and thus they are capable of receiving electrons from the coordinating olefin through a metal and of releasing electrons whenever required to expedite the olefin insertion process.

In addition, we have deliberately focused on non-symmetric ligands that possess an electronically flexible nature, since there had been less investigation into transition metal complexes bearing non-symmetric ligands as olefin polymerization catalysts when we initiated this research. We expected that such ligands might generate non-symmetric polymerization sites, resulting in the formation of polymeric materials with unique microstructures. Therefore, transition metal complexes bearing non-symmetric ligands and which have electronically flexible properties were considered to be viable catalysts for olefin polymerization ("ligand-oriented catalyst design research").

\subsection{Discovery of FI Catalysts}

A number of transition metal complexes were designed according to "ligand-oriented catalyst design research" investigated for their potential as ethylene polymerization catalysts at $25^{\circ} \mathrm{C}$ under atmospheric pressure using MAO as a cocatalyst.

As a result, we found that complex 1, bis[N-(3-tert-buty]salicylidene) anilinato] zirconium(IV) dichloride, demonstrates the highest activity of $519 \mathrm{~kg}-\mathrm{PE} / \mathrm{mmol}-\mathrm{cat} / \mathrm{h}$ (Table 1), which is more than 20 times higher than the activity 
Table 1. Ethylene polymerization activity of complexes $1-\mathbf{3}^{\mathrm{a}}$

\begin{tabular}{|c|c|c|c|}
\hline complex & 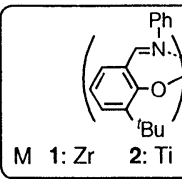 & $\mathrm{MCl}_{2}$ & $\mathrm{p}_{2} \mathrm{ZrCl}_{2}$ \\
\hline Activity $^{b}$ & 519 & 26 & 20 \\
\hline$M_{v}\left(\times 10^{3}\right)$ & $8 \quad 510$ & 17 & 950 \\
\hline
\end{tabular}

obtained with an early metallocene catalyst, $\mathrm{Cp}_{2} \mathrm{ZrCl}_{2} / \mathrm{MAO}$ (20 kg-PE/mmol-cat $/ \mathrm{h}$ ) under identical conditions. The activity exhibited by complex $\mathbf{1}$ is one of the highest values observed for homogeneous olefin polymerization catalysts, including group 4 metallocene catalysts and CGC, at atmospheric pressure conditions. Additionally, we revealed that its $\mathrm{Ti}$ and Hf congeners (complexes $\mathbf{2}$ and $\mathbf{3}$ ) with MAO also exhibit very high activities $(2 ; 3 \mathrm{~kg}-\mathrm{PE} / \mathrm{mmol}-\mathrm{cat} / \mathrm{h}, \mathbf{3} ; 26$ $\mathrm{kg}-\mathrm{PE} / \mathrm{mmol}-\mathrm{cat} / \mathrm{h}$ ). (Complexes 1-3 exhibit totally different catalytic properties when activated by ${ }^{i} \mathrm{Bu}_{3} \mathrm{Al} / \mathrm{Ph}_{3} \mathrm{CB}\left(\mathrm{C}_{6} \mathrm{~F}_{5}\right)_{4}$, which will be discussed later.) These results indicate that the combination of a group 4 transition metal and a phenoxyimine chelate ligand results in highly active ethylene polymerization catalysts. We have given the name "FI Catalysts" to the newly discovered phenoxy-imine ligated group 4 transition metal complexes after the Japanese pronunciation of the ligand "Fenokishi-Imin Haiishi". FI Catalysts also stands for Fujita group Invented Catalysts.

\subsection{Structures of FI Catalysts}

Because FI Catalysts have two bidentate non-symmetric phenoxy-imine ligands, they potentially possess five isomers. Complexes 1-3 display multiple sets of signals in ${ }^{1} \mathrm{H}$ NMR, attributed to the imine-proton, suggesting that these FI Catalysts exist as isomeric mixtures in solution, which is probably an intrinsic feature of FI Catalysts. On the basis of the

Scheme 2. RFE (kJ/mol) of the possible isomers of 1 .
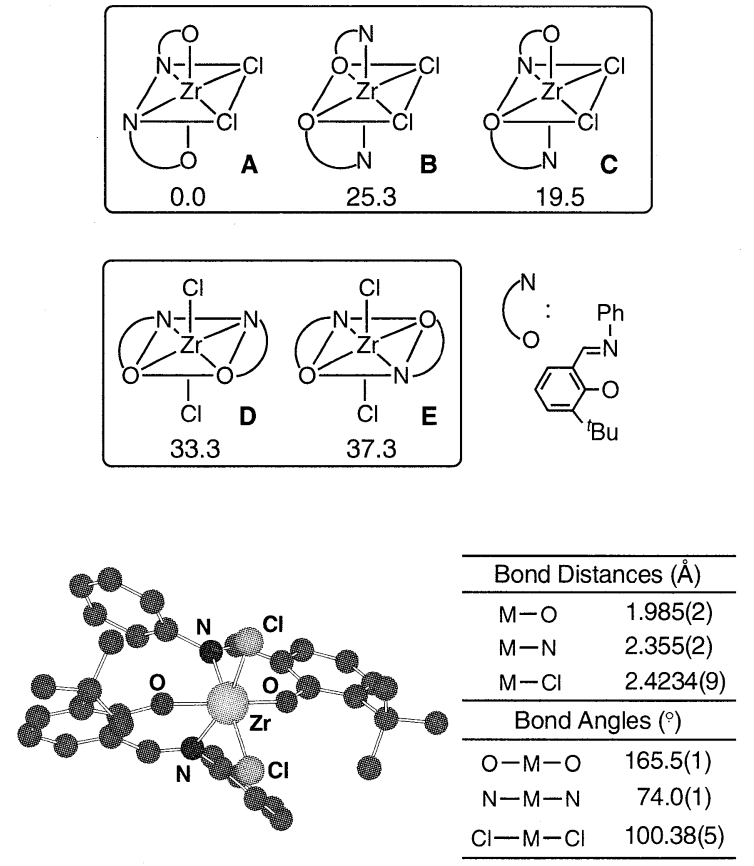

Figure 2. X-ray structure of complex 1. symmetry of the possible isomers $\mathbf{A}-\mathbf{E}$ (Scheme 2) as well as the relative formation energies (RFE) of the isomers (DFT calculations), we concluded that complex 1 predominantly exists as isomer $\mathbf{A}$ (trans ${ }^{-} \mathrm{O}, c_{i s}-\mathrm{N}$, and $c i s^{-} \mathrm{Cl}$ arrangement: $C_{2}$ symmetry) but some molecules exist as isomer $C\left(c^{-}-\mathrm{O}\right.$, cis ${ }^{-} \mathrm{N}$, and $c i s^{-} \mathrm{Cl}$ arrangement: $C_{1}$ symmetry) in solution. $\mathrm{X}$-ray crystallographic analysis demonstrates that, in the solid state, complex 1 possess an approximately octahedrally coordinated metal center and $C_{2}$ symmetry, with a trans $-\mathrm{O}$, cis $-\mathrm{N}$, and $c s^{-} \mathrm{Cl}$ disposition (isomer A, Scheme 2). These results show that FI Catalysts favor the isomer A structure, and they can be present as a mixture of isomers $\mathbf{A}$ and $\mathbf{C}$ in solution.

\subsection{Origin of the High Activity Displayed by FI Cata- lysts}

We postulated that the electronically flexible properties of the phenoxy-imine ligand are, in principle, responsible for the high activities of FI Catalysts. However, the ethylene polymerization activities obtained with FI Catalysts were very high, and, in fact, the value obtained for complex $\mathbf{1}$ was far beyond our expectations. Therefore, DFT calculations were performed in order to gain information about the cause of the very high activity observed. The calculations for an ethylene-coordinated methyl cationic complex, generated from $\mathbf{1}$ and MAO, for ethylene polymerization suggest that the cationic complex possesses a distorted octahedral geometry with a trans $^{-} \mathrm{O}$, cis $^{-} \mathrm{N}$ and cis $^{-} \mathrm{Me} /$ coordinated-ethylene (angle: $74.6^{\circ}$ disposition, Figure 3 ). This is potentially significant for achieving high activity because a crucial requirement for a high efficiency catalyst is to have a pair of cis located sites for polymerization. In addition, interestingly, the DFT calculations indicate that the $\mathrm{Zr}-\mathrm{N}$ bonds that lie in the same plane as the polymerization sites expand and contract according to the reaction coordinate of the ethylene insertion (2.23-2.34 $\AA$, Figure 3), whereas the $\mathrm{Zr}-\mathrm{O}$ bond length remains virtually unchanged. From studying these results, we believe that this variable $\mathrm{Zr}-\mathrm{N}$ bond length (which facilitates a smooth and flexible electron exchange between the metal and the ligands) and the cis located active sites, as well as the electronically flexible nature of the phenoxy-imine ligands, are responsible for the high polymerization activities of FI Catalysts.

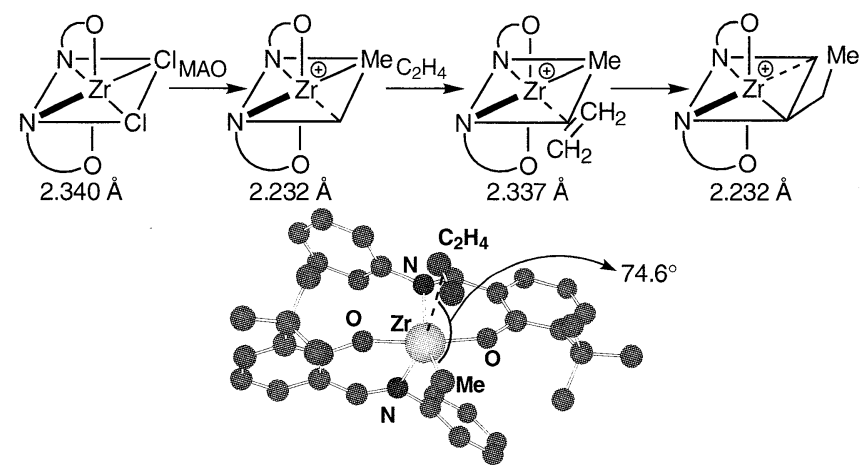

Figure 3. Calculated structure of active species from $\mathbf{1}$ and changes in $\mathrm{Zr}-\mathrm{N}$ bond length.

\section{Ethylene Polymerization}

\subsection{Increase in Polymerization Activity}

The ethylene polymerization activities of $\mathrm{Zr}-\mathrm{FI}$ Catalysts 
were enhanced by changing the ligand structures; in particular, the modification of the $\mathrm{R}^{2}$ substituent has a dramatic effect on the activity. Namely, $\mathrm{R}^{2}$ substituents that are less bulky than a tert-butyl group (i.e., ${ }^{i} \mathrm{Pr}, \mathrm{Me}$ ) noticeably reduce the activity (activity $<1 \mathrm{~kg}-\mathrm{PE} / \mathrm{mmol}-\mathrm{cat} / \mathrm{h}$ ). By contrast, $\mathrm{R}^{2}$ substituents that are larger than the ${ }^{t} \mathrm{Bu}$ group markedly enhance the activity (Figure 4). The activity is therefore directly correlated with the steric bulk of the $\mathrm{R}^{2}$ substituent. For example, in the sequence tert-butyl < adamantyl < cumyl $<1,1$-diphenylethyl, the activity increases from 311 $\mathrm{kg}-\mathrm{PE} / \mathrm{mmol}-\mathrm{cat} / \mathrm{h}\left(\mathrm{R}^{1}=\mathrm{Ph}, \mathrm{R}^{2}={ }^{t} \mathrm{Bu}, \mathrm{R}^{3}=\mathrm{Me}\right)$ to 2383 $\mathrm{kg}-\mathrm{PE} / \mathrm{mmol}-$ cat $/ \mathrm{h}\left(\mathrm{R}^{1}=\mathrm{Ph}, \mathrm{R}^{2}=1,1\right.$-diphenylethyl, $\left.\mathrm{R}^{3}=\mathrm{H}\right)$. With a cyclohexyl group in the $R^{1}$ position, the $R^{2}$ effect is more pronounced. A complex, which has cyclohexyl as $\mathrm{R}^{1}$, tert-butyl as $\mathrm{R}^{2}$ and methyl as $\mathrm{R}^{3}$, displays only 82 $\mathrm{kg}-\mathrm{PE} / \mathrm{mmol}-\mathrm{cat} / \mathrm{h}$ of activity, while the insertion of the 1,1-diphenylethyl group as $\mathrm{R}^{2}$ enhances the activity to 6552 $\mathrm{kg}-\mathrm{PE} / \mathrm{mmol}-\mathrm{cat} / \mathrm{h}$. This strikingly high activity corresponds to a catalyst turnover frequency (TOF) of $64900 / \mathrm{sec} / \mathrm{atm}$, which is two orders of magnitude greater than that seen with $\mathrm{Cp}_{2} \mathrm{ZrCl}_{2}$ under identical conditions. This TOF is probably the largest recorded, not only for olefin polymerization, but for any catalytic reaction under atmospheric pressure conditions.

Our rationalization of the significant effect of $R^{2}$ with regard to the activity enhancement is as follows;

1. The sterically encumbered $\mathrm{R}^{2}$ substituents give steric protection toward the oxygen-donors that are attached to the metal centers from coordination with Lewis acids such as MAO, or from another molecule of the catalytically active cationic species, which are supposed to be highly electrophilic. The coordination increases steric congestion near the polymerization center, which at least hampers ethylene coordination to the metal. Even worse, it may cause catalyst decay by, for instance, loss of the ligand.

2. Large $\mathrm{R}^{2}$ substituents induce effective ion-separation between the cationic active species and an anionic cocatalyst, which allows more space for ethylene coordination to the metal and for its insertion into the carbon-metal bond. In addition, electronically, the ion-separation increases the electrophilicity of the catalytically active species and hence enhances the reactivity towards ethylene.

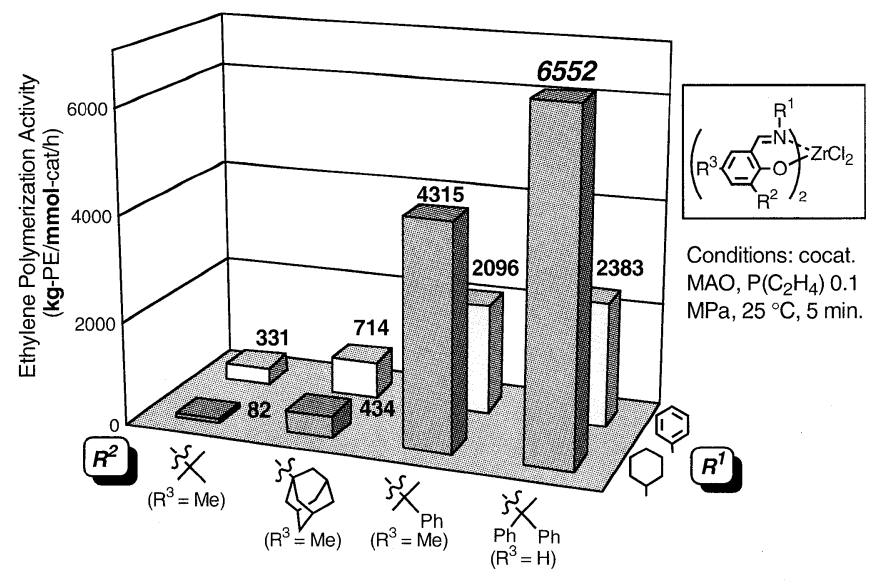

Figure 4. Increase of ethylene polymerization activities.

\subsection{Control of Polymer Molecular Weight}

\subsubsection{MAO Cocatalyst System}

Investigations into the control of PE molecular weights using $\mathrm{Zr}-\mathrm{FI}$ Catalysts with MAO indicated that these catalysts are viable for use in the production of very low to very high molecular weight PEs. As shown in Figure 5, by careful selection of the $\mathrm{R}^{1}$ and $\mathrm{R}^{2}$ substituents (and in particular the $\mathrm{R}^{1}$ substituent) controlled PE molecular weights between 1400 and 2,200,000 can be achieved while retaining high catalytic activities $(38-63 \mathrm{~kg}-\mathrm{PE} / \mathrm{mmol}-\mathrm{cat} / \mathrm{h})$. These results suggest that the $\mathrm{R}^{1}$ substituent is situated in close proximity to the active center. ${ }^{13} \mathrm{C}$ NMR as well as IR analyses demonstrate that the PEs produced using $\mathrm{Zr}-\mathrm{FI}$ Catalysts with MAO normally have a high degree of vinyl unsaturation at one of the two polymer-chain-ends, indicating that $\beta$-hydrogen transfer is the predominant chain termination process. Therefore, the $\mathrm{R}^{1}$ substituent plays a vital role in controlling the rate of $\beta$-hydrogen transfer.

The high efficiency selective synthesis of low molecular weight PEs containing predominantly vinyl chain ends is of great significance, since such PEs can serve as macromonomers in copolymerization with ethylene or $\alpha$-olefin to form long-chain branched polymers. Additionally, these PEs can be transformed by chain-end functionalization to produce end-functionalized PEs that are valuable intermediates for block copolymers containing PE and polar polymer segments.

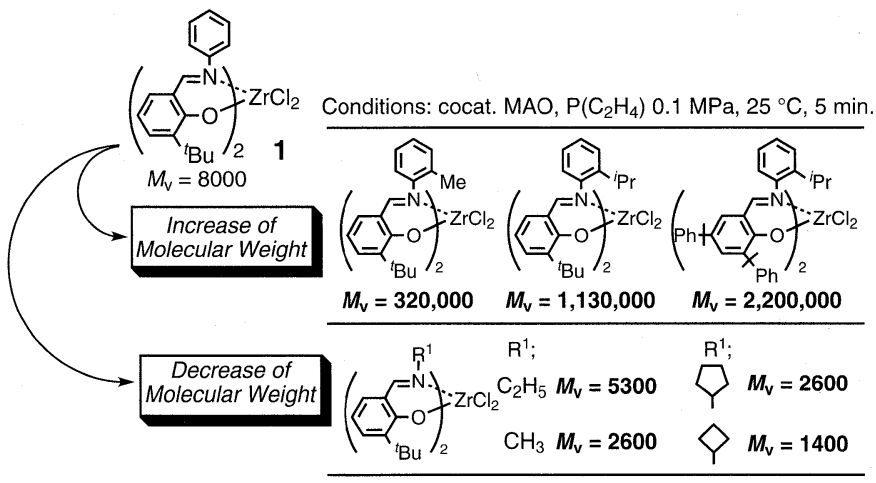

Figure 5. Control of polymer molecular weight by FI Catalysts.

\subsection{2 ${ }^{i} \mathrm{Bu}_{3} \mathrm{Al} / \mathrm{Ph}_{3} \mathrm{CB}\left(\mathrm{C}_{6} \mathrm{~F}_{5}\right)_{4}$ Cocatalyst System}

$\mathrm{Zr}-$ FI Catalysts, on activation with ${ }^{i} \mathrm{Bu} \mathrm{u}_{3} \mathrm{Al} / \mathrm{Ph}_{3} \mathrm{CB}\left(\mathrm{C}_{6} \mathrm{~F}_{5}\right)_{4}$, produce exceptionally high molecular weight $\mathrm{PEs}$, unlike the situation with MAO activation (Figure 6). For example, complex 1 in combination with ${ }^{i} \mathrm{Bu}_{3} \mathrm{Al} / \mathrm{Ph}_{3} \mathrm{CB}\left(\mathrm{C}_{6} \mathrm{~F}_{5}\right)_{4}$ at $50^{\circ} \mathrm{C}$ under atmospheric pressure forms a $\mathrm{PE}$ with the exceptionally high viscosity-average molecular weight $\left(M_{\mathrm{v}}\right)$ of $5,050,000$ and with a high activity of $11 \mathrm{~kg}-\mathrm{PE} / \mathrm{mmol}-\mathrm{cat} / \mathrm{h}$. This is one of the highest molecular weight PEs ever prepared. Likewise, many of the $\mathrm{Zr}-\mathrm{FI}$ Catalysts in combination with ${ }^{i} \mathrm{Bu}_{3} \mathrm{Al} / \mathrm{Ph}_{3} \mathrm{CB}\left(\mathrm{C}_{6} \mathrm{~F}_{5}\right)_{4}$ provide ultra-high molecular weight PEs $\left(M_{\mathrm{v}}>3,000,000\right)$ with notably high activities. $\mathrm{Zr}-\mathrm{FI}$ Catalysts in association with ${ }^{i} \mathrm{Bu}_{3} \mathrm{Al} / \mathrm{Ph}_{3} \mathrm{CB}\left(\mathrm{C}_{6} \mathrm{~F}_{5}\right)_{4}$ also generate high molecular weight ethylene-propylene copolymers (e.g., 1: $25^{\circ} \mathrm{C}$, atmospheric pressure, $M_{\mathrm{v}} 1,090,000$, propylene content $21 \mathrm{~mol} \%$, activity $8 \mathrm{~kg}$-polymer/mmol-cat $/ \mathrm{h}$ ). Since high molecular weight polymers display better mechanical properties, these ultra-high molecular weight PEs and very high molecular weight ethylene-propylene copolymers have many 


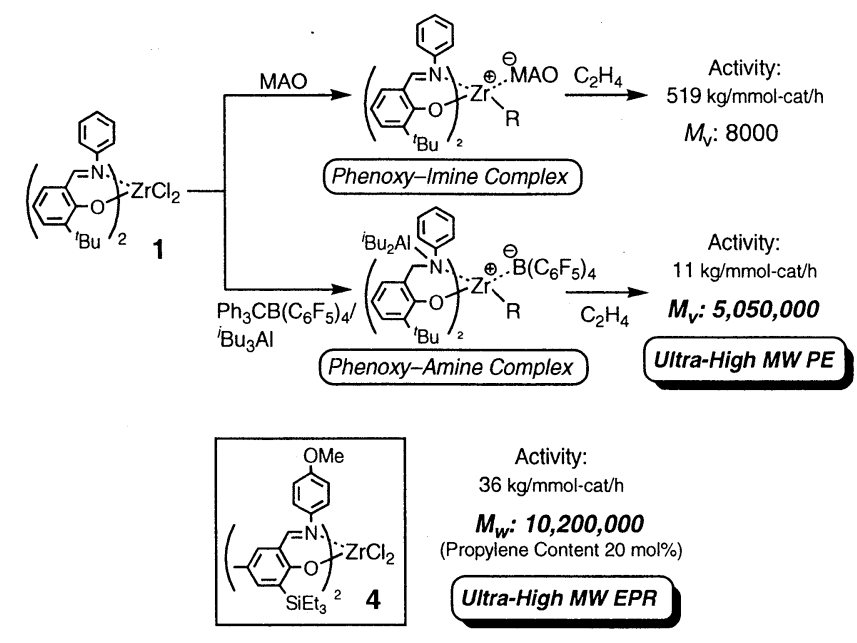

Figure 6. Ethylene or ethylene/propylene (co)polymerization with borate cocatalyst system.

potential applications.

Though the cocatalyst employed frequently influences the catalytic properties of the resulting catalyst system, the observed difference in molecular weight and catalytic activity between $\mathrm{MAO}$ and ${ }^{i} \mathrm{Bu}_{3} \mathrm{Al} / \mathrm{Ph}_{3} \mathrm{CB}\left(\mathrm{C}_{6} \mathrm{~F}_{5}\right)_{4}$ cocatalysts is highly unusual. Accordingly, we postulated that the localized structures of the active species are modified depending on which cocatalyst is employed. ${ }^{1} \mathrm{H}$ NMR studies of a mixture of complex 1 and ${ }^{i} \mathrm{Bu}_{3} \mathrm{Al}$ at $25^{\circ} \mathrm{C}$ indicated that the phenoxyimine ligand is reduced by ${ }^{i} \mathrm{Bu}_{3} \mathrm{Al}$ to a phenoxy-amine ligand with the co-production of isobutene. The addition of $\mathrm{Ph}_{3} \mathrm{CB}\left(\mathrm{C}_{6} \mathrm{~F}_{5}\right)_{4}$ and then ethylene gas to the resulting mixture in the NMR tube yielded PE. These results show that complex 1 with ${ }^{i} \mathrm{Bu}_{3} \mathrm{Al} / \mathrm{Ph}_{3} \mathrm{CB}\left(\mathrm{C}_{6} \mathrm{~F}_{5}\right)_{4}$ generates a bis(phenoxyamine) complex with a ${ }^{i} \mathrm{Bu}_{2} \mathrm{Al}$ group attached to the amine-donor as a catalytically active species, at least in the initial stages. Similar observations (i.e., imine reduction with ${ }^{i} \mathrm{Bu}_{3} \mathrm{Al}$ to form amine-functionality) were made for the corresponding $\mathrm{Ti}^{-}$and $\mathrm{Hf}-\mathrm{FI}$ Catalysts.

Interestingly, when complex 4 (which possesses a triethylsilyl, a methoxy and a methyl group in the ligand) is combined with ${ }^{i} \mathrm{Bu}_{3} \mathrm{Al} / \mathrm{Ph}_{3} \mathrm{CB}\left(\mathrm{C}_{6} \mathrm{~F}_{5}\right)_{4}$ under ethylene at atmospheric pressure at $25^{\circ} \mathrm{C}$, it yields a $\mathrm{PE}$ for which we are unable to determine either the molecular weight $\left(M_{\mathrm{w}}\right)$ or the viscosity-average molecular weight $\left(M_{\mathrm{v}}\right)$ due to its exceptionally low solubility in the solvent used for the measurements, suggesting a strikingly high molecular weight. The complex with ${ }^{i} \mathrm{Bu}_{3} \mathrm{Al} / \mathrm{Ph}_{3} \mathrm{CB}\left(\mathrm{C}_{6} \mathrm{~F}_{5}\right)_{4}$ at $70^{\circ} \mathrm{C}$ under $0.9 \mathrm{MPa}$ ethylene/ propylene total pressure forms an exceptional molecular weight amorphous ethylene-propylene copolymer with a uniform microstructure (propylene content $20 \mathrm{~mol} \%$ ) with an $M_{\mathrm{w}}$ of $10,200,000$ (vs PS standards) $\left(M_{\mathrm{w}} / M_{\mathrm{n}} 2.52\right)$, displaying a very high activity of $36 \mathrm{~kg}$-polymer $/ \mathrm{mmol}-\mathrm{cat} / \mathrm{h}$. The molecular weight represents the highest molecular weight known to date for a linear, synthetic copolymer. The resulting ultra-high molecular weight copolymers can be used as high-performance materials such as compatibilizers, additives and adhesives.

As shown, FI Catalysts can produce polymers with an extremely wide range of molecular weights by modification of their ligands or by selecting the appropriate cocatalyst. As far as we are aware, there is no other example where a cata- lyst system can control such a broad range of product molecular weights without the aid of chain transfer agents.

\subsection{Multimodal Behavior for Ethylene Polymerization}

As described, FI Catalysts potentially possess five isomers arising from coordination modes of ligands in an octahedral geometry, suggesting that FI Catalysts have the ability to produce well-defined multimodal polymers that are expected to possess an excellent combination of material properties and processability. In fact, in association with MAO, complex $\mathbf{5}$ forms uni-, bi- and tri-modal PEs in a controlled manner, simply by varying the polymerization temperatures (Figure 7). The polymerization characteristics as well as NMR studies on pre-catalysts suggest that the multimodal behavior originates from isomers of the catalytically active species. These are the first examples of well-defined bi- and tri-modal PEs originating from structural isomers that arise from different modes of ligand coordination. These results probably provide a unique strategy to produce well-defined multimodal polyolefins by a single homogeneous catalyst in a single stage polymerization process.

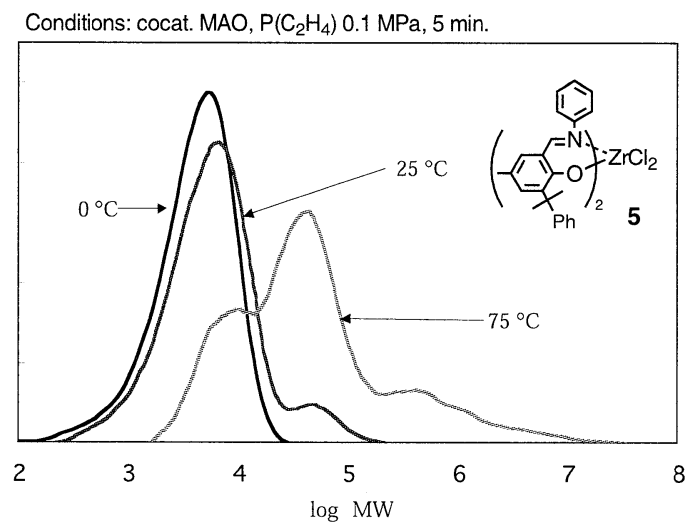

Figure 7. GPC profiles of PEs formed with complex 5/MAO.

\section{Propylene Polymerization}

\subsection{MAO Cocatalyst System}

Single-crystal $\mathrm{X}$-ray analysis demonstrates that molecule of complex 1 possesses approximately octahedrally- coordinated metal center and $C_{2}$ symmetry, as discussed. Thus, FI Catalysts were targeted as catalysts capable of producing iPP via a site-control mechanism.

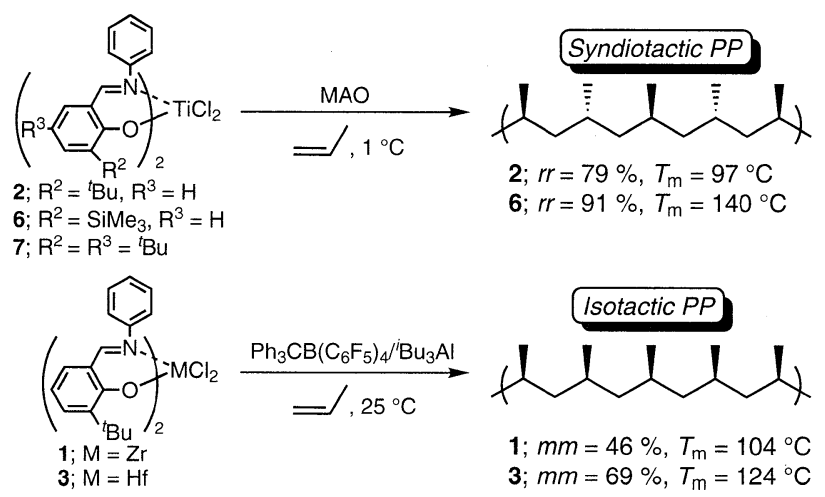

Figure 8. Propylene polymerization by FI Catalysts.

In combination with $\mathrm{MAO}, \mathrm{Zr}$ complex 1 and $\mathrm{Hf}$ complex 3 displayed fairly high reactivity towards propylene and 
formed propylene oligomers. On the other hand, the corresponding Ti complex 2 at $1{ }^{\circ} \mathrm{C}$ produced semi-crystalline PP, which exhibits a peak melting temperature of $97^{\circ} \mathrm{C}$, indicative of the formation of a stereoregular polymer (Figure 8). Surprisingly, microstructural analysis by ${ }^{13} \mathrm{C}$ NMR indicated that the resultant polymer is syndiotactic $(r r 79 \%)$, and that a chain-end control mechanism is responsible for the observed stereo-control, regardless of the $C_{2}$ symmetric catalyst.

Further research resulted in the discovery of complex $\mathbf{6}$, which possesses a trimethylsilyl group ortho to the phenoxy-oxygen, and which produces a highly syndiotactic PP ( $r r 91 \%)$ with a very high $T_{\mathrm{m}}$ of $140^{\circ} \mathrm{C}$ via a chain-end control mechanism. Such a high level of chain-end control was unprecedented in propylene polymerization.

We established the structure-catalytic performance (catalytic activity, product molecular weight and syndioselectivity) relationships of Ti-FI Catalysts with MAO activation, which have been reviewed or commented upon elsewhere. Based on combinatorial methods, Coates et al. have recently obtained a modified Ti-FI Catalyst (7), which has an additional ${ }^{t} \mathrm{Bu}$ group in the phenoxy-benzene ring. ${ }^{32 \mathrm{a}}$ This displays propylene polymerization behavior similar to $\mathbf{2}$ and produces moderately syndiotactic PPs. The results obtained by Coates et al. are consistent with the prediction based on the structure-catalytic performance relationships, indicating that a combinatorial approach can be used for the screening of catalysts for stereoselective propylene polymerization.

The formation of sPPs with $C_{2}$ symmetric Ti-FI Catalysts indicates that catalyst symmetry is not a rigid requirement for determining polymer stereochemistry. A propylene polymerization mechanism using Ti-FI Catalysts with MAO will be discussed in Section 6.3.

\section{2 ${ }^{i} \mathrm{Bu}_{3} \mathrm{Al} / \mathrm{Ph}_{3} \mathrm{CB}\left(\mathrm{C}_{6} \mathrm{~F}_{5}\right)_{4}$ Cocatalyst System}

On activation with ${ }^{i} \mathrm{Bu}_{3} \mathrm{Al} / \mathrm{Ph}_{3} \mathrm{CB}\left(\mathrm{C}_{6} \mathrm{~F}_{5}\right)_{4}$, FI Catalysts exhibit significantly different catalytic behavior for propylene polymerization, since the active species derived from these FI Catalyst systems are bis(phenoxy-amine) complexes. $\mathrm{Zr}$, Ti and Hf complexes $\mathbf{1}, \mathbf{2}$ and $\mathbf{3}$ were investigated as catalysts for the polymerization of propylene using ${ }^{i} \mathrm{Bu}_{3} \mathrm{Al} / \mathrm{Ph}_{3} \mathrm{CB}$ $\left(\mathrm{C}_{6} \mathrm{~F}_{5}\right)_{4}$ as a cocatalyst (Figure 8). Ti-FI Catalyst forms an ultra-high molecular weight atactic PP (aPP) $\left(M_{\mathrm{w}} 8,286,000\right.$, no $T_{\mathrm{m}}$ ) with a somewhat broad molecular weight distribution $\left(M_{\mathrm{w}} / M_{\mathrm{n}} 4.15\right)$. The molecular weight makes it one of the highest molecular weight PPs ever synthesized. Considering that one goal in polyolefin research has been to find catalysts that produce high molecular weight atactic polymers (because many aspecific catalysts make low molecular weight polymers) the discovery of the Ti-FI Catalyst system is highly significant. The high molecular weight aPPs may find applications as adhesives, compatibilizers and additives. By contrast, $\mathrm{Zr}$ and $\mathrm{Hf}$ complexes $\mathbf{1}$ and $\mathbf{3}$ produce high molecular weight $\left(1: M_{\mathrm{w}} 209,000, M_{\mathrm{w}} / M_{\mathrm{n}} 2.42,3: M_{\mathrm{w}} 412,000, M_{\mathrm{w}} / M_{\mathrm{n}}\right.$ 2.15) crystalline PPs that display $T_{\mathrm{m}} \mathrm{s}$ of $104^{\circ} \mathrm{C}$ (1) and $124^{\circ} \mathrm{C}$ (3). Microstructural analyses by ${ }^{13} \mathrm{C}$ NMR demonstrated that the resultant polymers are isotactic (1: $\mathrm{mm} \mathrm{46 \% ,} \mathrm{3:} \mathrm{mm}$ 69\%), and that the isoselective polymerization proceeds via a site-controlled mechanism. The Hf complex $3 /{ }^{i} \mathrm{Bu}_{3} \mathrm{Al} /$ $\mathrm{Ph}_{3} \mathrm{CB}\left(\mathrm{C}_{6} \mathrm{~F}_{5}\right)_{4}$ system is the first example of a non-metallocene $\mathrm{Hf}$-based catalyst system that forms iPP via an enantiomorphic site-control mechanism. Further efforts to develop highly isospecific FI Catalysts ${ }^{i} \mathrm{Bu}_{3} \mathrm{Al} / \mathrm{Ph}_{3} \mathrm{CB}\left(\mathrm{C}_{6} \mathrm{~F}_{5}\right)_{4}$ sys- tems have led to the discovery of $\mathrm{Zr}$ and $\mathrm{Hf}$ complexes that create highly isotactic PPs $\left(\mathrm{mmmm}>95 \%, 25^{\circ} \mathrm{C}\right.$ polymerization) with extremely high peak melting temperatures $\left(T_{\mathrm{m}}>\right.$ $\left.160^{\circ} \mathrm{C}\right)$.

These results mean that FI Catalysts have been demonstrated to provide PP architectures ranging from highly isotactic, atactic and highly syndiotactic via a chain-end- or a site-controlled mechanism by simple variations of the central metal, the ligand structure and the cocatalyst.

\section{Higher $\alpha$-Olefin Polymerization}

While Ti-FI Catalysts combined with MAO are poor catalysts for higher $\alpha$-olefin polymerization, on activation with ${ }^{i} \mathrm{Bu}_{3} \mathrm{Al} / \mathrm{Ph}_{3} \mathrm{CB}\left(\mathrm{C}_{6} \mathrm{~F}_{5}\right)_{4}$ Ti-FI Catalysts display unique polymerization behavior towards these olefins (Figure 9). The active species derived from $\mathrm{Ti}-\mathrm{FI}$ Catalysts with ${ }^{i} \mathrm{Bu}_{3} \mathrm{Al} / \mathrm{Ph}_{3} \mathrm{CB}\left(\mathrm{C}_{6} \mathrm{~F}_{5}\right)_{4}$ are suggested to be a phenoxy-amine ligated Ti complex, as already discussed. For instance, at $25^{\circ} \mathrm{C}$ complex 2 favors the 2,1-insertion of 1-hexene and produces high molecular weight $\left(M_{\mathrm{w}} 720,000, M_{\mathrm{w}} / M_{\mathrm{n}} 1.68\right)$ atactic poly(1-hexene)s having ca. $50 \mathrm{~mol} \%$ of regio-irregular units with high efficiency. Likewise, the same catalyst system forms high molecular weight atactic poly(1-octene)s $\left(M_{\mathrm{w}}\right.$ $\left.950,000, M_{\mathrm{w}} / M_{\mathrm{n}} 1.74\right)$, poly(1-decene)s $\left(M_{\mathrm{w}} 820,000, M_{\mathrm{w}} / M_{\mathrm{n}}\right.$ $1.75)$ and poly(4-methyl-1-pentene)s $\left(M_{\mathrm{w}} 1,400,000, M_{\mathrm{w}} / M_{\mathrm{n}}\right.$ 1.81 ), all of which include frequent regio-errors. As far as we know, the molecular weight of the poly(4-methyl-1-pentene) is the highest encountered for homogeneous olefin polymerization catalysts. Ethylene-higher $\alpha$-olefin copolymers possessing a wide variety of higher $\alpha$-olefin contents were synthesized with complex $2 /{ }^{i} \mathrm{Bu}_{3} \mathrm{Al} / \mathrm{Ph}_{3} \mathrm{CB}\left(\mathrm{C}_{6} \mathrm{~F}_{5}\right)_{4}$.

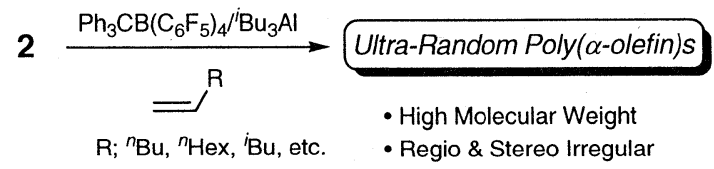

Figure 9. Polymerization of higher $\alpha$-olefins.

Considering that 2,1-insertion normally encourages chain termination (which causes low molecular weights) the production of high molecular weight regio-irregular poly(higher $\alpha$-olefin)s is of great significance. These represent the first examples of stereo- and regio-irregular high molecular weight poly(higher $\alpha$-olefin)s ("ultra-random polymers"). The ultra-random polymers may serve as adhesives and additives due to their high molecular weights as well as their sticky and transparent nature.

While the precise nature of the active species of the catalyst systems has not been elucidated, DFT calculations suggest that one of the amine-donors of the phenoxy-amine ligands is detached during the course of the polymerization, providing a wider space for polymerization.

Notably, the complex $2 /{ }^{i} \mathrm{Bu}_{3} \mathrm{Al} / \mathrm{Ph}_{3} \mathrm{CB}\left(\mathrm{C}_{6} \mathrm{~F}_{5}\right)_{4}$ system shows higher activities towards higher $\alpha$-olefins with sterically bulkier substituents (activity order; 4-methyl-1-pentene $>$ 1 -decene $>1$-octene $>1$-hexene). This highly unusual observation can be explained as follows: a sterically bulkier side chain derived from the last inserted higher $\alpha$-olefin of the growing polymer chain opens the phenoxy-amine ligands wider, which facilitates the coordination of the higher $\alpha$-olefin to the metal and its insertion into the metal-carbon 
bond. This postulate may provide a new strategy for the design of catalysts with high incorporation ability for sterically encumbered monomers.

\section{Living Polymerization}

The production of polymers with perfect control over the molecular weight, the composition and the architecture of the polymer has been a long-standing challenge for synthetic polymer chemists. Living olefin polymerization is a powerful tool for controlling the molecular weight as well as the composition and architecture of the polymer, and thus it can be used for the preparation of precisely controlled polymers (living polymers) such as monodisperse polymers, end-functionalized polymers and block copolymers. ${ }^{33}$ These precisely controlled polymers are anticipated to exhibit new or enhanced material properties and hence may have expanded utility.

However, living olefin polymerization catalysts usually only display living character at low polymerization temperatures (below room temperature), which favors the suppression of chain transfer reactions, and thus they exhibit low activities with insufficient molecular weights. In addition, it has not been possible to polymerize $\alpha$-olefins with useful stereoselectivity. Moreover, known catalysts normally initiate the living polymerization of either ethylene or $\alpha$-olefins but not both, which restricts the synthesis of polyolefinic block copolymers. Furthermore, living olefin polymerization catalysts give extremely low productivity compared with common olefin polymerization catalysts because each molecule of a catalyst only forms one polymer chain during the polymerization reaction.

FI Catalysts have allowed us to examine a wide variety of substituents including functional groups that typically contain heteroatoms. In exploring new derivatives of FI Catalysts, we have investigated FI Catalysts bearing halogen-containing ligands, which resulted in the discovery of fluorinated Ti-FI Catalysts that mediate the unprecedented living polymerization of both ethylene and propylene.

\subsection{Living Ethylene Polymerization}

As already reported, a common Ti-FI Catalyst with MAO possesses some characteristics of living ethylene polymerization under limited conditions (e.g., short polymerization time, controlled ethylene concentration in a polymerization medium). With complex 2 , monodisperse PEs $\left(M_{\mathrm{n}}<100,000\right)$ can be obtained (1 min polymerization, atmospheric pressure, $\left.25^{\circ} \mathrm{C} ; M_{\mathrm{n}} 52,100, M_{\mathrm{w}} / M_{\mathrm{n}} 1.12,50^{\circ} \mathrm{C} ; M_{\mathrm{n}} 64,900 M_{\mathrm{w}} / M_{\mathrm{n}} 1.17\right)$ with relatively low efficiency. In particular, phenoxy-ketimine type FI Catalysts display low activity ( 3 min polymerization, $\left.25^{\circ} \mathrm{C}, 10 \mathrm{psi} ; M_{\mathrm{n}} 21,300, M_{\mathrm{w}} / M_{\mathrm{n}} 1.04\right){ }^{32 \mathrm{f}}$

In contrast, fluorinated Ti complex 8 carries out highly controlled living ethylene polymerization at the high temperature of $50^{\circ} \mathrm{C}$ and furnishes very high molecular weight monodisperse PEs with strikingly high activities (Table 2, $M_{\mathrm{w}} / M_{\mathrm{n}} 1.13, M_{\mathrm{n}} 424,000$, TOF $\left.21,500 / \mathrm{min}\right)$. The living nature of the polymerization with $\mathbf{8} / \mathrm{MAO}$ was confirmed by the linear relationship between $M_{\mathrm{n}}$ and the polymerization time, as well as the narrow $M_{\mathrm{w}} / M_{\mathrm{n}}$ values observed (Figure 10). Significantly, there is virtually no chain termination or transfer operation in the catalyst system for at least $60 \mathrm{~min}$ at $25^{\circ} \mathrm{C}$, even in the absence of ethylene.

The $M_{\mathrm{n}}$ value of 424,000 represents one of the highest molecular weights among PEs produced in a living manner.
In addition, the TOF of $21,500 / \mathrm{min}$ is the highest activity reported to date with respect to living ethylene polymerization, and is comparable to those seen with early metallocenes, such as $\mathrm{Cp}_{2} \mathrm{ZrCl}_{2}$, under identical conditions. Considering that the MAO used as the cocatalyst is a potential chain transfer agent and that normally living olefin polymerization can only be achieved using a borate cocatalyst instead of $\mathrm{MAO}$, the fact that living ethylene polymerization with MAO is exhibited by the system at $50^{\circ} \mathrm{C}$ is highly significant. Notably, at $90^{\circ} \mathrm{C}$, complex $8 / \mathrm{MAO}$ produced PE with a fairly narrow molecular weight distribution $\left(M_{\mathrm{w}} / M_{\mathrm{n}} 1.30, M_{\mathrm{n}}\right.$ 167,000). Therefore, highly controlled living ethylene polymerization has been achieved with the fluorinated Ti complex 8.

Table 2. Ethylene living polymerization ${ }^{\text {a }}$ catalyzed by $8 / \mathrm{MAO}$

\begin{tabular}{|c|c|c|c|c|c|c|c|}
\hline entry & complex & $\begin{array}{l}\text { temp. } \\
\left({ }^{\circ} \mathrm{C}\right) \\
\end{array}$ & $\begin{array}{c}\text { time } \\
(\mathrm{min}) \\
\end{array}$ & $\begin{array}{l}\text { polymer } \\
\text { yield }(\mathrm{g})\end{array}$ & $\begin{array}{c}\text { TOF } \\
\left(\mathrm{min}^{-1}\right)\end{array}$ & $\begin{array}{r}M_{\mathrm{n}}^{\mathrm{b}} \\
\left(\times 10^{3}\right) \\
\end{array}$ & $M_{w} / M_{n}^{b}$ \\
\hline 1 & & 25 & 0.5 & 0.149 & 21,200 & 191 & 1.15 \\
\hline 2 & & 25 & 1 & 0.283 & 20,200 & 412 & 1.13 \\
\hline 3 & & 50 & 0.5 & 0.172 & 24,500 & 257 & 1.08 \\
\hline 4 & & 50 & 1 & 0.302 & 21,500 & 424 & 1.13 \\
\hline $5^{c}$ & & 75 & 1 & 0.453 & 16,100 & 272 & 1.15 \\
\hline $6^{d}$ & & 90 & 1 & 0.459 & 8,200 & 167 & 1.30 \\
\hline 7 & $\mathrm{Cp}_{2} \mathrm{ZrCl}_{2}$ & 25 & 1 & 0.258 & 18,400 & 157 & 1.73 \\
\hline 8 & $\mathrm{Cp}_{2} \mathrm{ZrCl}_{2}$ & 50 & 1 & 0.433 & 30,900 & 136 & 2.26 \\
\hline
\end{tabular}

${ }^{a}$ Conditions: cat. $0.5 \mu \mathrm{mol}$, cocat. $\mathrm{MAO} 1.25 \mathrm{mmol}, \mathrm{P}\left(\mathrm{C}_{2} \mathrm{H}_{4}\right) 0.1 \mathrm{MPa} .{ }^{\mathrm{b}}$ Determined by GPC using polyethylene calibration. ${ }^{\mathrm{C}}$ Cat. $1.0 \mu \mathrm{mol}$. ${ }^{\mathrm{d}}$ Cat. $2.0 \mu \mathrm{mol}$.

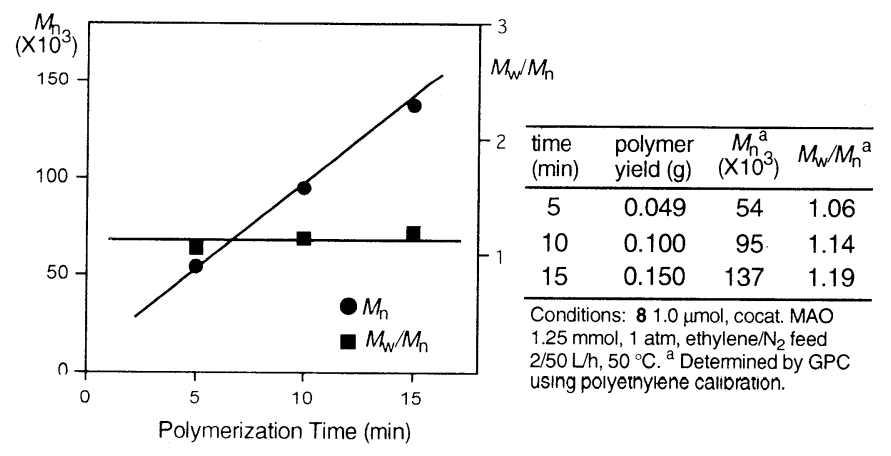

Figure 10. Plots of $M_{\mathrm{n}}$ and $M_{\mathrm{w}} / M_{\mathrm{n}}$ as a function of polymerization time for ethylene polymerization with complex 8/MAO at $50^{\circ} \mathrm{C}$.

\subsection{The Origin of Living Polymerization}

To gain information on the origin of this unprecedented living polymerization, we investigated the ethylene polymerization behavior of various fluorinated Ti-FI Catalysts. As summarized in Figure 11, complexes with ortho-F(s) (complexes 8-11) produce PEs with an extremely narrow molecular weight distribution $\left(M_{\mathrm{w}} / M_{\mathrm{n}} 1.05-1.11\right)$ whereas complexes 12-14 possessing no ortho-F generate PEs with $M_{\mathrm{w}} / M_{\mathrm{n}}$ values of approximately 2 under the conditions examined. These results demonstrate that the ortho-F is a requirement for living polymerization. In addition, end-group analyses of the PEs arising from non-living type FI Catalysts $\left(\mathrm{C}^{13} \mathrm{NMR}\right.$, IR) show the presence of almost equal amounts of vinyl and methyl chain-end groups, indicating that the predominant mechanism for chain termination with non-living type FI Catalysts is by $\beta$-hydrogen transfer. Therefore, the ortho-F suppresses the $\beta$-hydrogen transfer. DFT calculations were 
performed on an active species to elucidate the role of the ortho-F on living polymerization (Figure 12). At first we thought that the living nature originated from the stabilization of the $\mathrm{Ti}$ center by the ortho-F. However, the calculations show that the distance between the Ti and the ortho-F (the nearest F) is about $4 \AA$, which is too long to have an effective interaction. Alternatively, the ortho $-\mathrm{F}$ is revealed to interact with a $\beta$-hydrogen on a polymer chain (bond distance: $2.275 \AA$ ). The electrostatic energy between the negatively charged fluorine and the positively charged $\beta$-hydrogen is estimated to be a relatively large value, $27 \mathrm{~kJ} / \mathrm{mol}$. Additionally, a degree of $\mathrm{C}-\mathrm{H}_{\beta}$ bond elongation (1.113 $\AA$ ) was suggested by the calculations, which is probably the result of the interaction between the ortho-F with the $\beta$-hydrogen. This attractive interaction reduces the reactivity of the $\beta$-hydrogen towards the Ti metal and/or a reacting monomer, which prevents $\beta$-hydrogen transfer. This remarkable ortho-F effect represents a novel strategy for the design of a new transition metal complex for living olefin polymerization.

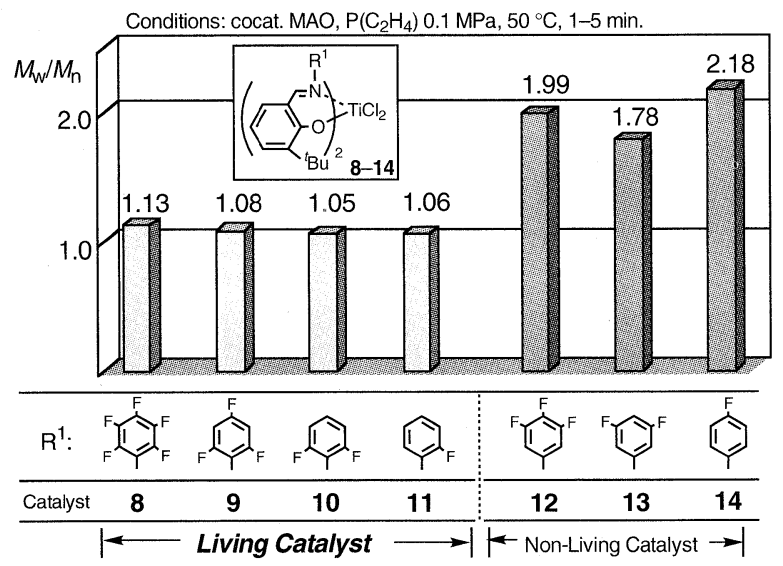

Figure 11. Ethylene polymerization catalyzed by 8-14.

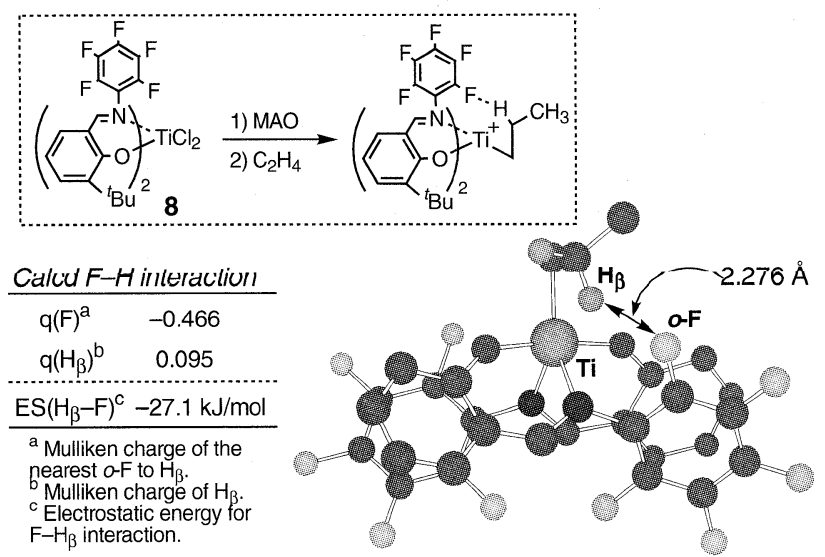

Figure 12. Structure of an active species derived from complex 8 calculated by DFT ( ${ }^{t} \mathrm{Bu}$ groups are omitted for clarity).

The ortho-F effect has been further confirmed by the fact that fluorinated $\mathrm{Zr}$ - and $\mathrm{Hf}-\mathrm{FI}$ Catalysts produce significantly enhanced (more than 20 times) molecular weight PEs and ethylene/propylene copolymers compared to the corresponding non-fluorinated FI Catalysts. Notably, Chan and co-workers have recently reported the first NMR and X-ray structural evidence for an attractive interaction between a fluorine in the ligand and a hydrogen on an alkyl group attached to the Ti center. ${ }^{34}$

\subsection{Stereospecific Living Propylene Polymerization}

Ti complex 8/MAO promotes the room-temperature living copolymerization of ethylene and propylene and provides high molecular weight monodisperse ethylene-propylene copolymers with varying propylene content $\left(M_{\mathrm{n}}>80,000\right.$, $M_{\mathrm{w}} / M_{\mathrm{n}} 1.07-1.13$, propylene content up to $\left.48 \%\right)$. These results suggest that the 8/MAO system might possess some characteristics of living propylene polymerization. For propylene polymerization with $\mathbf{8}$, the calculated attractive interaction between the ortho $-\mathrm{F}$ and the $\beta$-hydrogen is $46.8 \mathrm{~kJ} / \mathrm{mol}$ (1,2-insertion) or $30.7 \mathrm{~kJ} / \mathrm{mol}$ (2,1-insertion) depending on the insertion mode. These values indicate that the fluorinated Ti-FI Catalyst probably mediates living propylene polymerization.

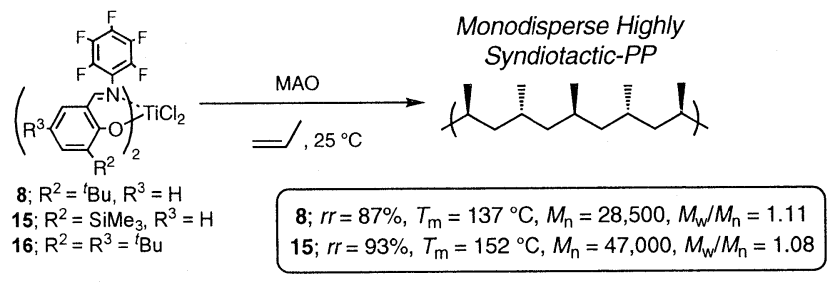

Figure 13. Highly syndiospecific living propylene polymerization.

As anticipated, complex 8 enabled room-temperature living propylene polymerization and produced PP with extremely narrow molecular weight distribution $\left(M_{\mathrm{w}} / M_{\mathrm{n}} 1.11, M_{\mathrm{n}}\right.$ $28,500)$ and high syndiotacticity $\left(r r 87 \%, T_{\mathrm{m}} 137^{\circ} \mathrm{C}\right)$ via a chain-end control mechanism (Figure 13). The living nature of the polymerization was confirmed by the linear increase in $M_{\mathrm{n}}$ with polymer yield. These results probably indicate that the attractive interaction capable of suppressing chain transfers sets a standard for controlled living polymerization of simple olefins via insertion chemistry.

It is worth noting that $\mathbf{8}$ displays higher syndioselectivity ( $r r 87 \%, 25^{\circ} \mathrm{C}$ polymerization) compared to the corresponding non-fluorinated Ti complex $2\left(r r 79 \%, 1^{\circ} \mathrm{C}\right.$ polymerization). Therefore, the introduction of the perfluorophenyl group contributed to the increase in stereoselectivity as well as the achievement of living propylene polymerization. Complex 8 is the first example of a simultaneous living and highly stereoselective catalyst for the polymerization of propylene. In addition, $\mathbf{8}$ is the first example of a catalyst that mediates the living polymerization of both ethylene and propylene.

The results of chain-end analyses of the resultant polymers using ${ }^{13} \mathrm{C}$ NMR suggest that syndiospecific propylene insertions occur with predominantly 2,1-regiochemistry; a phenomenon never previously observed for a group 4 metalbased catalyst. Predominant 2,1-insertion may be derived from steric congestion near the polymerization center due to a polymer chain and the ligand, which places the methyl group of the reacting propylene in the opposite direction to the polymer chain. Pellecchia, ${ }^{35}$ Coates $^{32 \mathrm{c}}$ and Busico ${ }^{36}$ have recently confirmed the generality of this highly unusual propylene polyinsertion mode with Ti-FI Catalysts.

Further research aimed at acquiring higher performance FI Catalysts for living propylene polymerization resulted in the discovery of an exceptional $\mathrm{Ti}$-FI Catalyst that provides much higher tacticity polymers with unprecedentedly high $T_{\mathrm{m}} \mathrm{s}$ via a chain-end control mechanism. Thus, complex 15, 
which incorporates a trimethylsilyl group ortho to the phenoxy-oxygen, yields highly syndiotactic monodisperse PP $\left(25^{\circ} \mathrm{C}, \operatorname{rr} 93 \%, M_{\mathrm{n}} 47000, M_{\mathrm{w}} / M_{\mathrm{n}} 1.08\right)$ with an extremely high $T_{\mathrm{m}}\left(152^{\circ} \mathrm{C}\right)$. Moreover, the polymer produced at $0{ }^{\circ} \mathrm{C}$ displays a $T_{\mathrm{m}}$ of $156^{\circ} \mathrm{C}(\mathrm{rr} 94 \%)$, which is among the highest values reported for sPPs. To our surprise, at $50^{\circ} \mathrm{C}, 15$ initiated living propylene polymerization and yielded monodisperse sPP with very high $T_{\mathrm{m}}$ of $150^{\circ} \mathrm{C}$, which represents the first example of living propylene polymerization at a temperature as high as $50^{\circ} \mathrm{C}$. The formation of high $T_{\mathrm{m}}$ sPPs is remarkable in view of the tremendous technological significance of such sPPs. Coates et al. have recently prepared a modified Ti-FI Catalyst 16, which possesses an additional ${ }^{t} \mathrm{Bu}$ group in the ligand, ${ }^{32 \mathrm{~b}}$ that exhibits practically the same catalytic performance for living propylene polymerization as the complex 16 and produces fairly syndiotactic PPs (16: $r r$ 86\%, $T_{\mathrm{m}}$ $135^{\circ} \mathrm{C}, 8: \operatorname{rr} 87 \%, T_{\mathrm{m}} 137^{\circ} \mathrm{C}, 25^{\circ} \mathrm{C}$ polymerization).

The high syndioselectivity displayed by the fluorinated Ti-FI Catalysts through chain-end control at room temperature or above is quite unusual, since normally chain-end control only operates well at very low to sub-ambient temperatures and loses its stereo-regulating capability at elevated temperatures.

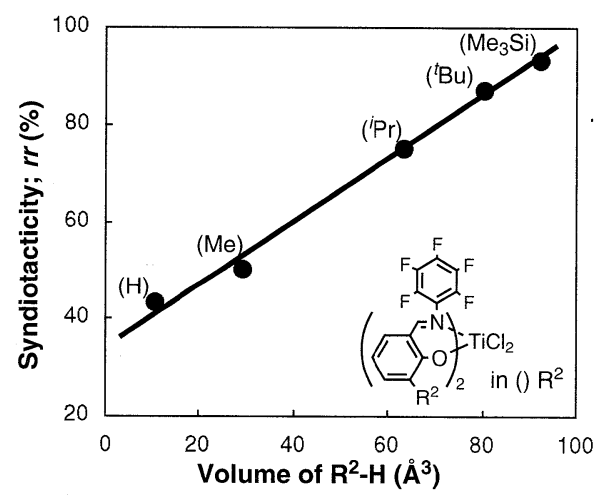

Figure 14. Plots of $r r$ triad values as a function of calculated $\mathrm{R}^{2}-\mathrm{H}$ volume for propylene polymerization $\left(25^{\circ} \mathrm{C}\right.$, coca $\mathrm{MAO})$.

Further investigations into the propylene polymerization behavior of Ti-FI Catalysts have revealed that the steric bulk of the substituent that is ortho to the phenoxy-oxygen controls the syndioselectivity of the polymerization, as demonstrated by the linear relationship between the volume of the ortho-substituent $\left(\mathrm{R}^{2}\right)$ and the syndioselectivity ( $\mathrm{H}: \mathrm{rr} 43 \%$, Me: $r r 50 \%,{ }^{i} \mathrm{Pr}$ : $r r 75 \%,{ }^{t} \mathrm{Bu}: r r 87 \%, \mathrm{Me}_{3} \mathrm{Si}$ : $r r 93 \%, 25^{\circ} \mathrm{C}$ polymerization, Figure 14). A striking feature observed is that despite the chain-end control mechanism, the ligand structure has a dramatic effect on the tacticity and the sterically encumbered ortho-substituent results in highly syndiospecific, thermally robust living propylene polymerization. Therefore, we have given the name "ligand-directed chain-end control polymerization" to this type of chain-end controlled polymerization that is evidently governed by the ligand structures. With ligand-directed chain-end control polymerization, atactic- to highly-syndiotactic PPs can now be prepared in a living manner with Ti-FI Catalysts. The PPs produced possess regio-block structures, which are classified into two types; one involving consecutive regio-irregular units (highly syndiotactic PPs) and the other having isolated regio-irregular units (atactic to syndiotactic-rich PPs).

While the exact cause for the unexpected and very high syndioselectivity through chain-end control is not clear at the present time, the syndioselectivity can be explained by the combination of the rapid site-inversion proposed by Cavallo et $a l .{ }^{37}$ and the attractive interaction between the ligand and the growing polymer chain discussed herein.

\subsection{Syntheses of Well-defined Block Copolymers}

One of the most attractive features of a living olefin polymerization catalyst system lies in its capability to create well-defined polyolefinic block copolymers. As described, fluorinated Ti-FI Catalysts can efficiently synthesize PEs, ethylene-propylene copolymers (EPRs), aPPs and sPPs in a living manner, allowing the creation of block copolymers with various architectures from ethylene and propylene, which has been a long-standing scientific challenge. We have thus demonstrated the utility of the fluorinated Ti-FI Catalysts through the syntheses of both ethylene- and propylene-based block copolymers consisting of crystalline and amorphous segments and/or two different kinds of crystalline segments (Table 3), most of which were inaccessible prior to our work.

For instance, a PE- $b$-EPR diblock consisting of crystalline PE and amorphous EPR segments was synthesized from ethylene and ethylene/propylene. The addition of MAO and complex 8 to an ethylene saturated toluene at $25^{\circ} \mathrm{C}$ resulted in the rapid formation of a living PE $\left(M_{\mathrm{n}} 115,000, M_{\mathrm{w}} / M_{\mathrm{n}}\right.$ $1.10)$. The addition of ethylene/propylene (1/3 volume ratio) to this living PE formed a PE- $b$-EPR block copolymer $\left(M_{\mathrm{n}}\right.$ $211,000, M_{\mathrm{w}} / M_{\mathrm{n}} 1.16$, propylene content $6.4 \mathrm{~mol} \%$ ). The polymer exhibits a $T_{\mathrm{m}}$ of $123^{\circ} \mathrm{C}$, which is lower than the corresponding PE $\left(133^{\circ} \mathrm{C}\right)$. The decrease in $T_{\mathrm{m}}$ of the block copolymer is probably due to the fact that the crystalline state is disturbed by the segregation process of incompatible components composed of crystalline PE and amorphous EPR segments, (which are chemically linked) further con-

Table 3. Synthesis of various block copolymers

\begin{tabular}{|c|c|c|c|c|c|c|c|c|c|c|c|}
\hline \multirow[b]{2}{*}{ entry } & \multicolumn{2}{|c|}{ prepolymer } & \multirow[b]{2}{*}{$\begin{array}{l}T_{m}^{b} \\
\left({ }^{\circ} \mathrm{C}\right)\end{array}$} & \multicolumn{3}{|c|}{ diblock copolymer } & \multirow[b]{2}{*}{$\begin{array}{l}T_{\mathrm{m}}{ }^{\mathrm{b}} \\
\left({ }^{\circ} \mathrm{C}\right)\end{array}$} & \multicolumn{3}{|c|}{ triblock copolymer } & \multirow[b]{2}{*}{$\begin{array}{l}T_{\mathrm{m}}^{\mathrm{b}} \\
\left({ }^{\circ} \mathrm{C}\right)\end{array}$} \\
\hline & 1st block & $\mathrm{k} M_{n}^{\mathrm{a}}, M_{w} / M_{n}^{\mathrm{a}}$ & & 2nd block & $M_{\mathrm{n}}{ }^{\mathrm{a}}, M_{\mathrm{w}} M_{\mathrm{n}}{ }^{\mathrm{a}}$ & $\begin{array}{l}\text { propylene } \\
\text { content }\end{array}$ & & 3rd block & $M_{n}{ }^{a}, M_{w} / M_{n}{ }^{a}$ & $\begin{array}{l}\text { propylene } \\
\text { content }\end{array}$ & \\
\hline 1 & $P E^{d}$ & $115,000,1.10$ & 133 & $\mathrm{PP}^{\mathrm{e}}$ & $136,000,1.15$ & 16.1 & 131 & - & - & - & \\
\hline 2 & $\uparrow$ & $\uparrow$ & 4 & $E / P^{i}$ & $211,000,1.16$ & 6.4 & 123 & - & - & - & \\
\hline 3 & 4 & 4 & $\uparrow$ & 4 & 4 & $\uparrow$ & $\uparrow$ & PP & $235,000,1.15$ & 14.1 & 123 \\
\hline 4 & 4 & $i$ & 4 & $i$ & $i$ & $\uparrow$ & $i$ & $\mathrm{PE}$ & $272,000,1.14$ & 6.6 & 120 \\
\hline 5 & PP & $27,000,1.13$ & 137 & $E / P$ & $161,000,1.51$ & 40.3 & 127 & - & - & - & \\
\hline
\end{tabular}


firming the formation of the targeted block copolymer.

Likewise, PE- $b$-sPP, sPP- $b$-EPR, PE- $b-\mathrm{EPR}-b-\mathrm{sPP}$ and PE- $b$-EPR- $b$-PE block copolymers were also prepared with the 8/MAO system by the sequential addition of the corresponding monomers. Thus, the usefulness of FI Catalysts/MAO systems for the syntheses of a wide array of block copolymers has been demonstrated. The PE- $b$-EPR and $\mathrm{SPP}-b-\mathrm{EPR}$ were analyzed by atomic force microscopy (AFM) and transmission electron microscopy (TEM) ${ }^{25 b}$ to demonstrate their high potential as novel materials. The unique block copolymers formed with the FI Catalysts have potential uses in a broad spectrum of applications including compatibilizers, elastomers and composite materials. Coates et al. have recently prepared sPP- $b$-EPR (similar to that synthesized by us) using a modified Ti-FI Catalyst 16 at $0^{\circ} \mathrm{C}^{32 b}$.

\subsection{Catalytic Production of Living Polymers}

Fluorinated Ti-FI Catalysts have achieved some of the crucial goals regarding polymer syntheses using living olefin polymerization (i.e., syntheses of high molecular weight monodisperse PEs and PPs, highly syndiotactic monodisperse PPs and a variety of unique block copolymers from ethylene and propylene). Although these living polymers possess many potential applications in various fields as new materials, living-type FI Catalysts suffer from low catalyst productivity. This is because such FI Catalysts can only produce one polymer chain during the polymerization, rendering the living polymers arising from the FI Catalysts economically nonviable.

Therefore, an important goal that still remains to be realized is the catalytic production of living polymers, that increases the polymer/catalyst ratio and thus enhances catalyst productivity. The catalytic production of living polymers is feasible if we develop FI Catalysts that incorporate monomers without termination, even in the presence of a chain transfer agent (CTA), and which only undergo chain transfer in the absence of a reacting monomer. The development of such FI Catalysts would appear to be difficult. However, with their highly controlled living nature, the required FI Catalysts can be obtained by controlling the reactivity of FI Catalysts towards a reacting monomer and a chain transfer agent.

Initial attempts were unsuccessful due to catalyst decomposition and/or undesirable chain termination induced by the chain transfer agent employed. However, elaborate catalyst design work focusing on the substitution pattern of fluorines as well as the selection of the substituent ortho to the phenoxy-oxygen, has resulted in the discovery of FI Catalysts that are capable of catalytically producing living polymers in combination with chain transfer agents (e.g., $\mathrm{H}_{2}, \mathrm{Et}_{2} \mathrm{Zn}$ ).

For example, the catalytic production of $\mathrm{Zn}$-terminated PEs was achieved by complex 17 . The polymerization procedures are summarized in Scheme 3. The first step was saturation of the reaction medium with ethylene, followed by living ethylene polymerization (A). $\mathrm{Et}_{2} \mathrm{Zn}$ (80 eq to 17) was then added to the reaction medium (B), followed by ethylene polymerization once again $(\mathrm{C})$. Quenching the reaction after (A) afforded monodisperse PE (polymer (X), $M_{\mathrm{n}} 36,700, M_{\mathrm{w}} / M_{\mathrm{n}}$ 1.20) whereas quenching following the complete sequence (polymerization $(\mathrm{A})-(\mathrm{C})$ ) provided an approximately double yield of PE with virtually the same molecular weight and molecular weight distribution (polymer (Y), $M_{\mathrm{n}} 37,100$,
$\left.M_{\mathrm{w}} / M_{\mathrm{n}} 1.31\right)$. This is the first example of the production of multiple living polymer chains per catalyst. This chemistry provides a convenient and efficient route to catalytically preparing monodisperse $\mathrm{Zn}$-terminated polyolefins, which opens up countless opportunities for the syntheses of functionalized polyolefins or block copolymers containing polyolefin and polar polymer segments.

Scheme 3. Catalytic production in living polymerization system.
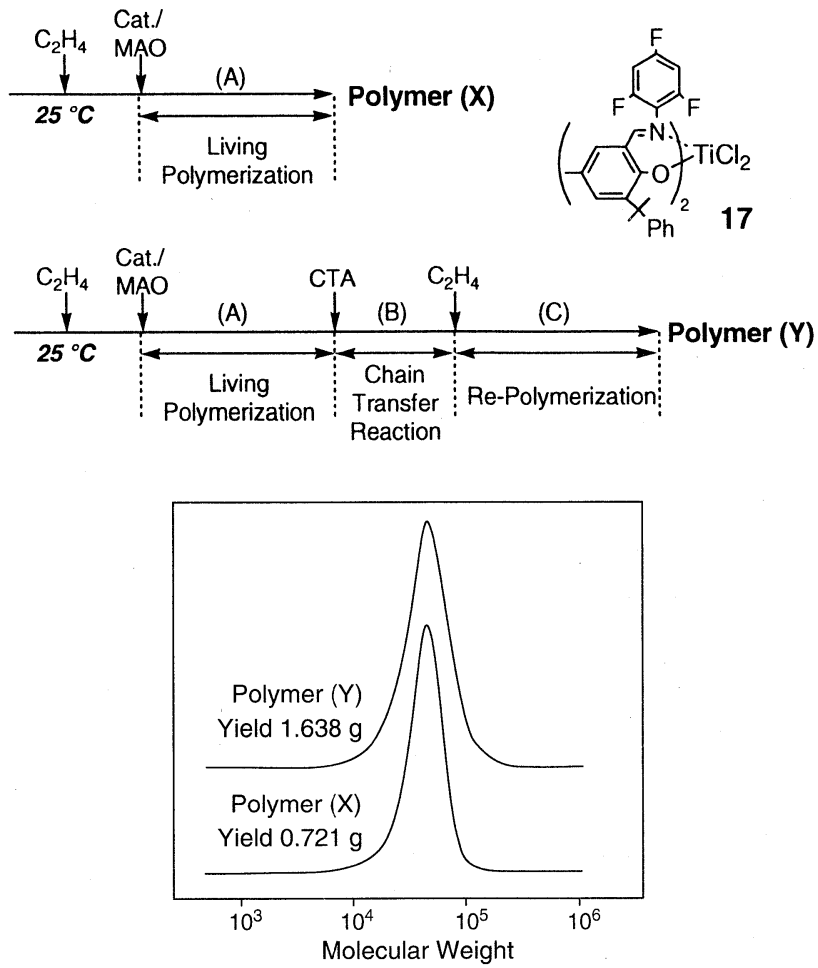

Figure 15. GPC profile of polyethylenes obtained by 17 (CTA; $\left.\mathrm{Et}_{2} \mathrm{Zn}\right)$. Polymer $(\mathrm{X}) ; M_{\mathrm{n}} 36,700, M_{\mathrm{w}} / M_{\mathrm{n}} 1.20$, Polymer $(\mathrm{Y}) ; M_{\mathrm{n}} 37,100, M_{\mathrm{w}} / M_{\mathrm{n}} 1.31$.

Similarly, with complex 9 , catalytic production of monodisperse PEs and PE- $b$-EPR was accomplished for the first time using $\mathrm{H}_{2}$ as a chain transfer agent. The combination of specifically designed FI Catalysts with appropriate chain transfer agents will provide a new strategy for the catalytic production of living polymers. The strategy is expected to render the displacement of some of the existing polyolefin-based materials by high-performance living polymers economically viable.

\section{Polyolefin-Based Materials created by FI Catalysts (Summary)}

Quite a few FI Catalysts have been synthesized so far, and these possess a variety of ligand architectures. Such FI Catalysts have created a wide range of polyolefinic materials with a wide variety of microstructures. The polyolefinic materials produced with the catalyst systems are summarized in Table 4 , where one can recognize that many of these polymers arising from FI Catalysts are either difficult or impossible to synthesize using conventional Ziegler-Natta catalysts. These achievements regarding polymer syntheses depend highly on both recent advances in rational catalyst design with the aid of computational science represented by DFT calculations and the wide range of catalyst design possibilities that are afforded by FI Catalysts. These possibilities are derived from 
the readily-varied steric and electronic properties of the phenoxy-imine ligands. It is expected that future research on FI Catalysts will provide opportunities to produce additional polyolefin-based materials with unique microstructures and related properties.

Table 4. Examples of various polyolefins created by FI Catalysts

\begin{tabular}{llc}
\hline \multirow{2}{*}{ Catalyst } & \multicolumn{2}{c}{ Cocatalyst } \\
\cline { 2 - 3 } Zr Complex & $\begin{array}{l}\text { Very Low-High MW PEs } \\
\text { Well-Defined } \\
\text { Multimodal PEs }\end{array}$ & $\begin{array}{c}\text { Ultra-High MW } \\
\text { PEs \& EPRs }\end{array}$ \\
& \multicolumn{1}{c}{ Highly iso-PPs } \\
\hline \multirow{3}{*}{ Ti Complex $\left.\mathrm{F}_{5}\right)_{4} / \mathrm{Bu}_{3} \mathrm{Al}$}
\end{tabular}

\section{FI Catalysts with $\mathrm{MgCl}_{2}-$ Based Cocatalyst Systems}

The development of highly active $\mathrm{MgCl}_{2}$-supported $\mathrm{TiCl}_{4}$ catalyst systems for olefin polymerization at Mitsui and at Montecatini in the late 1960 s revolutionized the polyolefin industry due to the cost effectiveness originating from a simplified production process and the superior material properties of the polyolefins produced. ${ }^{38}$ Kinetic analyses have revealed that $\mathrm{MgCl}_{2}$, originally used as a support, increases the rate constant of the chain propagation as well as the amount of active species, and, therefore, $\mathrm{MgCl}_{2}$ not only functions as a support but also as a good cocatalyst for titanium chloride catalysts. Therefore, the development of $\mathrm{MgCl}_{2}$-supported $\mathrm{TiCl}_{4}$ catalyst systems implies the discovery of a $\mathrm{MgCl}_{2}$ cocatalyst. We have postulated that the enhancement of the rate constant for chain propagation (cocatalytic performance) stems from a direct (but possibly weak) electronic interaction between the active $\mathrm{Ti}$ species and the $\mathrm{MgCl}_{2}$. Since FI Catalysts possess $\mathrm{O}$ and $\mathrm{N}$ heteroatoms in the ligands that are capable of clcctronically interacting with $\mathrm{MgCl}_{2}$, we expected that $\mathrm{MgCl}_{2}$ would work as a cocatalyst for FI Catalysts. Thus, a decision has been made to investigate $\mathrm{MgCl}_{2}$ as a cocatalyst for the FI Catalysts in the hope of developing additional high-performance FI Catalyst systems.

The ability of $\mathrm{MgCl}_{2} /{ }^{i} \mathrm{Bu}_{\mathrm{m}} \mathrm{Al}(\mathrm{OR})_{\mathrm{n}}$ (prepared by the dealcoholysis of a $\mathrm{MgCl}_{2} / 2$-ethyl-1-hexanol (EHA) adduct with ${ }^{i} \mathrm{Bu}_{3} \mathrm{Al}$ ) to mediate the polymerization of ethylene in association with Ti-FI Catalysts was investigated. Some of the results are tabulated in Table 5. Ti complexes $\mathbf{2 , 1 8}$ and 19 with $\mathrm{MgCl}_{2}$-based compounds exhibit high activities (21-36 kg-PE/mmol-cat/h) comparable to those obtained with the corresponding MAO cocatalyst system. Significantly, the catalyst systems produce particles with good morphology, suggesting that the Ti-FI Catalysts employed are immobilized on the cocatalyst surface. These results indicate that an $\mathrm{MgCl}_{2}$-based compound not only works as a good cocatalyst but also as an effective support for FI Catalysts. Thus, FI Catalysts $/ \mathrm{MgCl}_{2}$-based compounds have the potential for control of polymer morphology.

In particular, these complexes $/ \mathrm{MgCl}_{2}$ cocatalyst systems give narrow molecular weight distributions $\left(M_{\mathrm{w}} / M_{\mathrm{n}}\right.$ 2.40-2.67) consistent with single-site behavior. As far as we
Table 5. Ethylene polymerizationa with complexes 2, 18, 19, using $\mathrm{MgCl}_{2}$-based cocatalyst

\begin{tabular}{|c|c|c|c|c|}
\hline complex & Cocatalyst $^{b}$ & Activity $^{c}$ & $M_{w}^{d}\left(\times 10^{3}\right)$ & $M_{w} / M_{n}^{d}$ \\
\hline 2 & $\mathrm{MgCl}_{2} / \mathrm{Bu}_{m} \mathrm{Al}(\mathrm{OR})_{n}$ & 36 & 509 & 2.66 \\
\hline 18 & $\mathrm{MgCl}_{2} /{ }^{\prime} \mathrm{Bu} m \mathrm{Al}(\mathrm{OR})_{n}$ & 21 & 596 & 2.67 \\
\hline 19 & $\mathrm{MgCl}_{2} /{ }^{\prime} \mathrm{Bu} m_{m} \mathrm{Al}(\mathrm{OR})_{n}$ & 36 & 231 & 2.40 \\
\hline 2 & MAO & 45 & 464 & 2.38 \\
\hline 18 & MAO & 21 & 625 & 2.74 \\
\hline 19 & MAO & 99 & 229 & 2.07 \\
\hline
\end{tabular}

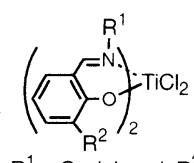

18; $R^{1}=$ Cyclohexyl, $R^{2}={ }^{t} \mathrm{Bu}$ $19 ; R^{1}=R^{2}=P h$

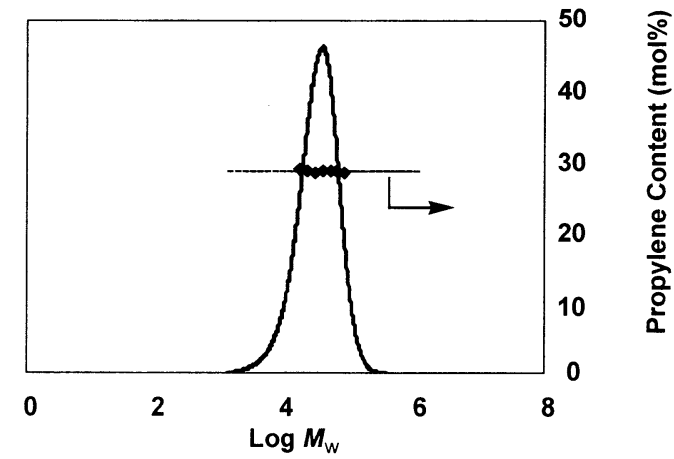

Figure 16. GPC-IR chart of the ethylene-propylene copolymer arising from complex 19 using $\mathrm{MgCl}_{2} /{ }^{i} \mathrm{Bu}_{\mathrm{m}} \mathrm{Al}(\mathrm{OR})_{\mathrm{n}}$ cocatalyst.

are aware, these are the first examples of MAO- and fluoroaryl-based-compound-free, highly active, single-site catalysts bascd on a transition metal complex and an $\mathrm{MgCl}_{2}$ cocatalyst. The single-site nature of the catalyst system has been further confirmed by the copolymerization of ethylene with propylene that forms a uniform copolymer with narrow molecular weight distribution (propylene content: $29.3 \mathrm{~mol} \%$, $M_{\mathrm{w}} / M_{\mathrm{n}} 1.70$ ) and narrow compositional distribution (Figure 16). Further studies have revealed that $\mathrm{MgCl}_{2}$-based compounds can also be good cocatalysts for $\mathrm{Zr}-\mathrm{FI}$ Catalysts. For instance, $\mathrm{Zr}$ complex 20 with $\mathrm{MgCl}_{2} l^{i} \mathrm{Bu}_{\mathrm{m}} \mathrm{Al}(\mathrm{OR})_{\mathrm{n}}$ displays an exceptionally high ethylene polymerization activity of 1800 $\mathrm{kg}-\mathrm{PE} / \mathrm{mmol}-\mathrm{cat} / \mathrm{h}\left(50^{\circ} \mathrm{C}, 0.9 \mathrm{MPa}\right)$. To our knowledge, this is the highest activity reported to date for ethylene polymerization mediated by MAO- and fluoroarylboron-free catalyst systems.

\section{Conclusion}

Ligand-oriented catalyst design research has led to the discovery of FI Catalysts, which are based on non-symmetric phenoxy-imine chelate ligands combined with group 4 transition metals. FI Catalysts in association with MAO or ${ }^{i} \mathrm{Bu}_{3} \mathrm{Al} / \mathrm{Ph}_{3} \mathrm{CB}\left(\mathrm{C}_{6} \mathrm{~F}_{5}\right)_{4}$ display unique polymerization catalysis and are capable of producing a wide variety of value-added polymers with distinctive microstructures by variation of the 
central metal and the ligand structure. Many of these polymers were previously unobtainable with conventional Ziegler-Natta catalysts, and they include very low to exceptionally high molecular weight PEs and ethylene/ $\alpha$-olefin copolymers, monodisperse to controlled multimodal PEs and PPs, stereo- and regio-irregular high molecular weight poly(higher $\alpha$-olefin)s, highly syndiotactic to highly isotactic PPs and ethylene- and propylene-based various polyolefinic block copolymers. Thus, FI Catalysts have been widening the scope of the polyolefinic materials accessible by transition metal-based catalytic technology. In addition, we recently discovered that FI Catalysts with $\mathrm{MgCl}_{2}$-based cocatalysts can be used as MAO- and fluoroarylboron-free high-performance single-site catalyst systems, which has opened up new possibilities for creating additional value-added polyolefin-based materials. It is now clear that the advent of FI Catalysts for olefin polymerization has initiated a revolution in the field of polymerization catalysis and thus polymer synthesis.

Acknowledgments We are grateful to J. Saito, S. Matsui, Y. Tohi, Y. Yoshida, Y. Suzuki, H. Makio, S. Ishii, J. Mohri, R. Furuyama, N. Matsukawa, S. Matsuura, Y. Sonobe, Y. Takagi, K. Tsuru, H. Terao, M. Nitabaru, T. Matsugi, H. Kaneko, S. Matsuo, S. Kojoh, T. Nakano, H. Tanaka, and A. Valentine for their research and technical assistance.

\section{References}

1) (a) Sinn, H.; Kaminsky, W.; Vollmer, H. J.; Woldt, R. Angew. Chem., Int. Ed. Engl. 1980, 19, 390. (b) Kaminsky, W.; Külper, K.; Brintzinger, H. H.; Wild, F. R. W. P. Angew. Chem., Int. Ed. Engl. 1985, 97, 507. (c) Kaminsky, W. Catal. Today 1994, 20, 257. (e) Möhring, P. C.; Coville, N. J. J. Organomet. Chem. 1994, 479, 1. (f) Brintzinger, H. H.; Fischer, D.; Mülhaupt, R.; Rieger, B.; Waymouth, R. M. Angew. Chem., Int. Ed. Engl. 1995, 34, 1143. (g) Bochmann, M. J. Chem. Soc. Dalton Trans. 1996, 255.

2) (a) Britovsek, G. J. P.; Gibson, V. C.; Wass, D. F. Angew. Chem., Int. Ed. 1999, 38, 428. (b) Ittel, S. D.; Johnson, L. K.; Brookhart, M. Chem. Rev. 2000, 100, 1169. (c) Gibson, V. C.; Spitzmesser, S. K. Chem. Rev. 2003, 103, 283. (d) Suzuki, Y.; Terao, H.; Fujita, T. Bull. Chem. Soc. Jpn. 2003, 76, 1493.

3) (a) Miyatake, T.; Mizunuma, K.; Seki, Y.; Kakugo, M. Makromol. Chem., Rapid Commun. 1989, 10, 349. (b) der Linden, A. V.; Schaverien, C. J.; Meijboom, N.; Ganter, C. J.; Orpen, A. G. J. Am. Chem. Soc. 1995, 117, 3008.

4) (a) Johnson, L. K.; Killian, C. M.; Brookhart, M. J. Am. Chem. Soc. 1995, 117, 6414. (b) Johnson, L. K.; Mecking, S.; Brookhart, M. J. Am. Chem. Soc. 1996, 118, 267. (c) Gates, D. P.; Svejda, S. A.; Onate, E.; Killian, C. M.; Johnson, L. K.; White, P. S.; Brookhart, M. Macromolecules 2000, 33, 2320.

5) (a) Scollard, J. D.; McConville, D. H.; Payne, N. C.; Vittal, J. J. Macromolecules 1996, 29, 5241. (b) Scollarad, J. D.; McConville, D. H. J. Am. Chem. Soc. 1996, 118, 10008. (c) Scollard, J. D.; McConville, D. H.; Vittal, J. J.; Payne, N. C. J. Mol. Catal. A 1998, 128, 201.

6) (a) Baumann, R.; Davis, W. M.; Schrock, R. R. J. Am. Chem. Soc. 1997, 119, 3830. (b) Liang, L. C.; Schrock, R. R.; Davis, W. M. Organometallics 2000, 19, 2526. (c) Baumann, R.; Davis, W. M.; Schrock, R. R. J. Am. Chem. Soc. 1997, 119, 3830. (d) Jeon, Y-M.; Park, S. J.; Heo, J.; Kim, K. Organometallics 1998, 17,3161 .

7) (a) Nomura, K.; Naga, N.; Takaoki, K. Macromolecules 1998, 31, 8009. (b) Nomura, K.; Sagara, A.; Imanishi, Y. Macromolecules 2002, 35,1583.

8) Boussie, T. R.; Diamond, G. M.; Goh, C.; Hall, K. A.; LaPointe, A. M.; Leclerc, M.; Lund, C.; Murphy, V.; Shoemaker, J. A. W.; Tracht, U.; Turner, H.; Zhang, J.; Uno, T.; Rosen, R. K.; Stevens, J. C. J. Am. Chem. Soc. 2003, 125, 4306.

9) Stephan, D. W.; Guerin, F.; Spence, R. E. V. H.; Koch, L.; Gao, X.; Brown, S. J.; Swabey, J. W.; Wang, Q.; Xu, W.; Zoricak, P.; Harrison, D. G. Organometallics 1999, 18, 2046.
10) (a) Small, B. L.; Brookhart, M.; Bennett, A. M. A. J. Am. Chem. Soc. 1998, 120, 4049. (b) Small, B. L.; Brookhart, M. J. Am. Chem. Soc. 1998, 120, 7143. (c) Small, B. L.; Brookhart M. Macromolecules 1999, 32, 2120.

11) (a) Britovsek, G. J. P.: Gibson, V. C.; Kimberley, B. S.; Maddox, P. J.; McTavish, S. J.; Solan, G. A.; White, A. J. P.; Williams, D. J. Chem. Commun. 1998, 849. (b) Britovsek, G. J. P.; Bruce, M.; Gibson, V. C.; Kimberly, B. S.; Maddox, P. J.; Mastroianni, S.; Mctarish, S. J.; Redshaw, C.; Solan, G. A.; Strömberg, S.; White, A. J. P.; Williams, G. J. J. Am. Chem. Soc. 1999, 121, 8728.

12) Murtuza, S.; Casagrande Jr, O. L.; Jordan, R. F. Organometallics 2002, 21, 1882.

13) Hakala, K.; Lofgren, B.; Polamo, M.; Leskela, M. Macromol. Rapid Commun. 1997, 18, 635.

14) (a) Wang, C.; Friedrich, S.; Younkin, T. R.; Li, R. T.; Grubbs, R. H.; Bansleben, D. A.; Day, M. W. Organometallics 1998, 17, 3149. (b) Younkin, T. R.; Connor, E. F.; Henderson, J. I.; Friedrich, S. K.; Grubbs, R. H.; Bansleben, D. A. Science 2000, 287, 460 .

15) Averbuj, C.; Tish, E.; Eisen, M. S. J. Am. Chem. Soc. 1998, 120, 8640 .

16) (a) Tshuva, E. Y.; Goldberg, I.; Kol, M.; Weitman, H.; Goldschmidt, Z. Chem. Commun. 2000, 379. (b) Tshuva, E. Y.; Goldberg, I.; Kol, M. J. Am. Chem. Soc. 2000, 122, 10706.

17) Matsuo, Y.; Mashima, K.; Tani, K. Chem. Lett. 2000, 1114.

18) Chan, M. C. W.; Tam, K-H.; Pui, Y-L.; Zhu, N. J. Chem. Soc., Dalton Trans. 2002, 3085.

19) (a) Chen, E.-Y.; Marks, T. J. Chem. Rev. 2000, 100, 1391. (b) Hlatkey, G. G. Chem. Rev. 2000, 100, 1347. (b) Strauss, S. H. Chem. Rev. 1993, 93, 927. (c) Soga, K.; Uozumi, T.; Kishi, N. Macromol. Rapid Commun. 1995, 16, 793. (d) Lee, D. H.; Shinn, S. Y. Int. Appl. WO9809996. (e) N. Kishi, C-H. Ahn, J. Jin, T. Uozumi, T. Sano, K. Soga, Macromol. Rapid Commun. 2000, 21, 775 .

20) (a) Matsui, S.; Fujita, T. Catal. Today 2001, 66, 63. (b) Makio, H.; Kashiwa, N.; Fujita, T. Adv. Synth. Catal. 2002, 344, 477. (c) Matsukawa, N.; Mitani, M.; Fujita, T. Kobunshi Ronbunshu 2002, 59, 158.

21) (a) Fujita, T.; Tohi, Y.; Mitani, M.; Matsui, S.; Saito, J.; Nitabaru, M.; Sugi, K.; Makio, H.; Tsutsui, T. Eur. Pat. 1998, 0874005. (b) Mitani, M.; Yoshida, Y.; Mohri, J.; Tsuru, K.; Ishii, S.; Kojoh, S.; Matsugi, T.; Saito, J.; Matsukawa, N.; Matsui, S.; Nakano, T.; Tanaka, H.; Kashiwa, N.; Fujita, T. WO Pat. 2001, 55231 A1.

22) (a) Matsui, S; Tohi, Y.; Mitani, M.; Saito, J.; Makio, H.; Tanaka, H.; Nitabaru, M.; Nakano, T.; Fujita, T. Chem. Lett. 1999, 1065. (b) Matsui, S.; Mitani, M.; Saito, J.; Tohi, Y.; Makio, H.; Tanaka, H.; Fujita, T. Chem. Lett. 1999 1263. (c) Matsui, S.; Mitani, M.; Saito, J.; Matsukawa, N.; Tanaka, H.; Nakano, T.; Fujita, T. Chem. Lett. 2000, 554. (d) Saito, J.; Mitani, M.; Matsui, S.; Kashiwa, N.; Fujita, T. Macromol. Rapid Commun. 2000, 21, 1333. (e) Matsukawa, N.; Matsui, S.; Mitani, M.; Saito, J.; Tsuru, K.; Kashiwa, N.; Fujita, T. J. Mol. Catal. A 2001, 169, 99. (f) Matsui, S.; Mitani, M.; Saito, J.; Tohi, Y.; Makio, H.; Matsukawa, N.; Takagi, Y.; Tsuru, K.; Nitabaru, M.; Nakano, T.; Tanaka, H.; Kashiwa, N.; Fujita, T. J. Am. Chem. Soc. 2001, 123, 6847. (g) Saito, J.; Mitani, M.; Matsui, S.; Tohi, Y.; Makio, H.; Nakano, T.; Tanaka, H.; Kashiwa, N.; Fujita, T. Macromol. Chem. Phys. 2002, 203, 59. (h) Ishii, S.; Saito, J.; Mitani, M.; Mohri, J.; Matsukawa, N.; Tohi, Y.; Matsui, S.; Kashiwa, N.; Fujita, T. J. Mol. Catal. A 2002, 179, 11. (i) Ishii, S.; Mitani, M.; Saito, J.; Matsuura, S.; Kojoh, S.; Kashiwa, N.; Fujita, T. Chem. Lett. 2002, 740. (j) Ishii, S.; Saito, J.; Matsuura, S.; Suzuki, Y.; Furuyama, R.; Mitani, M.; Nakano, T.; Kashiwa, N.; Fujita, T. Macromol. Rapid Commun. 2002, 23, 693. (k) Saito, J.; Onda, M.; Matsui, S.; Mitani, M.; Furuyama, R.; Tanaka, H.; Fujita, T. Macromol. Rapid Commun. 2002, 23, 1118. (1) Saito, J.; Mitani, M.; Onda, M.; Mohri, J.; Ishii, S.; Yoshida, Y.; Nakano, T., Kashiwa, N.; Fujita, T. Stud. Surf. Sci. Catal. 2003, 145, 515. (m) Tohi, Y.; Matsui, S.; Makio, H.; Onda, M.; Fujita, T. Macromolecules 2003, 36, 523. (n) Furuyama, R.; Saito, J.; Ishii, S.; Mitani, M.; Matsui, S.; Tohi, Y.; Makio, H.; Matsukawa, N.; Tanaka, H.; Fujita, T. J. Mol. Catal. A 2003, 200, 31. (o) Saito, J.; Suzuki, Y.; Fujita, T. Chem. Lett. 2003, 32, 236. (p) Ishii, S.; Mitani, M.; Saito, J.; Matsuura, S.; Furuyama, R.; Fujita, T. Stud. Surf. Sci. Catal. 2003, 145, 49. (q) Matsukawa, N.; Ishii, S.; Furuyama, R.; Saito, J.; Mitani, M.; Makio, H.; 
Tanaka H.; Fujita, T. e-Polymers 2003, No. 021 (http://www.ePolymers.org).

23) Suzuki, Y.; Kashiwa, N.; Fujita, T. Chem. Lett. 2002, 358.

24) (a) Saito, J.; Mitani, M.; Mohri, J.; Yoshida, Y.; Matsui, S.; Ishii, S.; Kojoh, S.; Kashiwa, N.; Fujita, T. Angew. Chem., Int. Ed. 2001, 40, 2918. (b) Mitani, M.; Mohri, J.; Yoshida, Y.; Saito, J.; Ishii, S.; Tsuru, K.; Matsui, S.; Furuyama, R.; Nakano, T.; Tanaka, H.; Kojoh, S.; Matsugi, T.; Kashiwa, N.; Fujita, T. J. Am. Chem. Soc. 2002, 124, 3327. (c) Mitani, M.; Nakano, T.; Fujita, T. Chem. Eur. J. 2003, 9, 2396. (d) Mitani, M.; Fujita, T. ACS Symposium Series Volume No. 857, Beyond Metallocenes. Next-generation Polymerization Catalysts, American Chemical Society: Washington, DC, 2003; 26. (e) Mitani, M.; Mohri, J.; Furuyama, R.; Ishii S.; Fujita, T. Chem. Lett. 2003, 32,238 .

25) (a) Saito, J.; Mitani, M.; Mohri, J.; Ishii, S.; Yoshida, Y.; Matsugi, T.; Kojoh, S.; Kashiwa, N.; Fujita, T. Chem. Lett. 2001, 576. (b) Kojoh, S.; Matsugi, T.; Saito, J.; Mitani, M.; Fujita, T.; Kashiwa, N. Chem. Lett. 2001, 822. (c) Saito, J.; Mitani, M.; Onda, M.; Mohri, J.; Ishii, S.; Yoshida, Y.; Nakano, T.; Tanaka, H.; Matsugi, T.; Kojoh, S.; Kashiwa, N.; Fujita, T. Macromol. Rapid Commun. 2001, 22, 1072. (d) Mitani, M.; Furuyama, R.; Mohri, J.; Saito, J.; Ishii, S.; Terao, H.; Kashiwa, N.; Fujita, T. J. Am. Chem. Soc. 2002, 124, 7888. (e) Mitani, M.; Furuyama, R.; Mohri, J.; Saito, J.; Ishii, S.; Terao, H.; Nakano, T.; Tanaka, H.; Fujita, T. J. Am. Chem. Soc. 2003, 125, 4293.

26) (a) Nakayama, Y.; Bando, H.; Sonobe, Y.; Kaneko, H.; Kashiwa, N.; Fujita, T. J. Catal. 2003, 215, 171. (b) Nakayama, Y; Bando, H.; Sonobe, Y.; Suzuki, Y.; Fujita, T. Chem. Lett. 2003, 32, 766. (c) Bando, H.; Nakayama, Y.; Sonobe, Y.; Fujita, T. Macromol. Rapid Commun. 2003, 24, 732.

27) (a) Yoshida, Y.; Matsui, S.; Takagi, Y.; Mitani, M.; Nitabaru, M.; Nakano, T.; Tanaka, H.; Fujita, T. Chem. Lett. 2000, 1270. (b) Yoshida, Y.; Matsui, S.; Takagi, Y.; Mitani, M.; Nakano, T.; Tanaka, H.; Kashiwa, N.; Fujita, T. Organometallics 2001, 20 , 4793. (c) Yoshida, Y.; Saito, J.; Mitani, M.; Takagi, Y.; Matsui, Ishii, S.; S.; Nakano, T.; Kashiwa, N.; Fujita, T. Chem. Commun. 2002, 1298. (d) Matsui, S.; Spaniol, T. P.; Takagi, Y.; Yoshida, Y.; Okuda, J. J. Chem. Soc., Dalton Trans. 2002, 4529. (e) Yoshida, Y.; Nakano, T.; Tanaka, H.; Fujita, T. Israel J. Chem. 2002, 42, 353.

28) (a) Matsugi, T.; Matsui, S.; Kojoh, S.; Takagi, Y.; Inoue, Y.; Fujita, T.; Kashiwa, N. Chem. Lett. 2001, 566. (b) Matsugi, T.; Kojoh, S.; Fujita, T.; Kashiwa, N. Kobunshi Ronbunshu 2002, 59, 410. (c) Matsugi, T.; Matsui, S.; Kojoh, S.; Takagi, Y.; Inoue, Y.; Fujita, T.; Kashiwa, N. Macromolecules 2002, 35, 4880.

29) (a) Inoue, Y.; Nakano, T.; Tanaka, H.; Kashiwa, N.; Fujita, T. Chem. Lett. 2001, 1060. (b) Suzuki, Y.; Inoue, Y.; Tanaka, H.; Kashiwa, N.; Fujita, T. Abstracts of $90^{\text {th }}$ Catalyst Society of Japan Meeting 2002, 3E21, Hamamatsu, Japan, Sep. 18-21, 2002. (c) Takagi, Y.; Mitani, M.; Fujita, T. Abstracts of $49^{\text {th }}$ Symposium on Organometallic Chemistry, Japan 2002, PA2110,
Kobe, Japan, Sep. 12-13, 2002.

30) (a) Cozzi, P. G.; Gallo, E.; Floriani, C.; Chiesi-Villa, A.; Rizzoli, C. Organometallics 1995, 14, 4994. (b) Tjaden, E. B.; Swenson, D. C.; Jordan, R. F. Organometallics 1995, 14, 371. (c) Tsukahara, T.; Swenson, D. C.; Jordan, R. F. Organometallics 1997, 16, 3303. (d) Kim, I; Nishihara, Y.; Jordan, R. F.; Rogers, R. D.; Rheingold, A. L.; Yap, G. P. A. Organometallics 1997, 16, 3314.

31) (a) Strauch, J.; Warren, T. H.; Erker, G.; Frohlich, R.; Saarenketo, P. Inorg. Chim. Acta 2000, 300-302, 810. (b) Huang, J.; Lian, B.; Qian, Y.; Zhou, W.; Chen, W.; Zheng, G. Macromolecules 2002, 35, 4871. (c) Corden, J. P.; Errington, W.; Moore, P.; Wallbridge, M. G. H. Chem. Commun. 1999, 323. (d) Woodman, P. R.; Munslow, I. J.; Hitchcock, P. B.; Scott, P. K. J. Chem. Soc., Dalton Trans. 1999, 4069. (e) Woodman, P. R.; Alcock, N. W.; Munslow, I. J.; Sanders, C. J.; Scott, P. J. Chem. Soc., Dalton Trans. 2000, 3340. (f) Gibson, V. C.; Mastroianni, S.; Newton, C.; Redshaw, C.; Solan, G. A.; White, A. J. P.; Williams, D. J. J. Chem. Soc., Dalton Trans. 2000, 1969. (g) Emslie, D. J. H.; Piers, W. E.; MacDonald, R. J. Chem. Soc., Dalton Trans. 2002, 293. (h) Emslie, D. J. H.; Piers, W. E.; Parvez, M.; MacDonald, R. Organometallics 2002, 21, 4226. (i) Knight, P. D.; Clarke, A. J.; Kimberley, B. S.; Jackson, R. A.; Scott, P. Chem. Commun. 2002, 352. (j) Jones, D. J.; Gibson, V. C.; Green, S. M.; Maddox, P. J.; Chem. Commun. 2002, 1038. (k) Rieger, B.; Troll, C.; Preuschen, J. Macromolecules 2002, 35, 5742 .

32) (a) Tian, J.; Coates, G. W. Angew. Chem., Int. Ed. 2000, 39, 3626. (b) Hustad, P. D.; Tian, J.; Coates, G. W. J. Am. Chem. Soc. 2001, 123, 5134. (c) Tian, J.; Hustad, P. D.; Coates, G. W. J. Am. Chem. Soc. 2002, 124, 3614. (d) Hustad, P. D.; Coates, G. W. J. Am. Chem. Soc. 2002, 124, 11578. (e) Fujita, M.; Coates, G. W. Macromolecules 2002, 35, 9640. (f) Reinartz, S.; Mason, A. F.; Lobkovsky, E. B.; Coates, G. W. Organometallics 2003, 22, 2542.

33) For a recent review see; Coates, G. W.; Hustad, P. D.; Reinartz, S. Angew. Chem., Int. Ed. 2002, 41, 2236.

34) Kui, S. C. F.; Zhu, N.; Chan, M. C. W. Angew. Chem. Int. Ed. 2003, 42, 1628.

35) Lamberti, M.; Pappalardo, D.; Zambelli, A.; Pellecchia, C. Macromolecules 2002, 35, 658.

36) Talarico, G.; Busico, V.; Cipullo, R.; Cavallo, L. J. Am. Chem. Soc. 2003, 125, 7172 .

37) Milano, G.; Cavallo, L.; Guerra, G. J. Am. Chem. Soc. 2002, 124,13368

38) (a) Ziegler, K.; Gallert, H. G.; Zosel, K.; Lehmkuhl, W.; Pfohl, W. Angew. Chem. 1955, 67, 424. (b) Ziegler, K.; Holzkamp, E.; Breil, H.; Martin, H. Angew. Chem. 1955, 67, 541. (c) Kashiwa, N.; Tokumizu, T.; Fujimura, H. U.S. Pat. 1968, 3642746. (d) Strauss, S. H. Chem. Rev. 1993, 93, 927. (e) Reed, C. A.; Acc. Chem. Res. 1998, 31, 133. (f) Galli, P.; Vecellio, G. Prog. Polym. Sci. 2001, 26, 1287. 


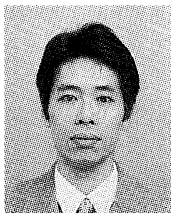

Yasushi Nakayama was born in November 1968 in Kanagawa, Japan. He graduated in catalysis chemistry from the Tokyo Institute of Technology where he received his M. S. degree in 1993, working with Prof. Ken-ichi Aika. He joined Mitsui Petrochemical Industries, Ltd. (now Mitsui Chemicals, Inc.) as a researcher. His research interests have been focused on "the development of new olefin polymerization catalyst systems for new or advanced polyolefin materials". He is a recipient of the Chemical Society of Japan Award for Young Chemists in Technical Development for 2002 .

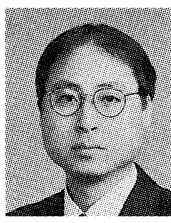

Makoto Mitani is chief researcher at Mitsui Chemicals, Inc. He was born in July 1963 in Kyoto and received his B. S. (1987) and M. S. degrees (1989) in industrial chemistry from Kyoto University, working with Professor Kiichiro Uchimoto. He Joined Mitsui Petrochemical Industries (now Mitsui Chemicals, Inc.) in 1989. He obtained his Ph.D. degree in organometallic chemistry and polymer chemistry from Kyoto University in 1997. He received the Chemical Society of Japan Award for Young Chemists in Technical Development for 2000. His research interests include organometallic chemistry, olefin polymerization catalysts and polymer chemistry.
Hideki Bando was born in February 1976 in Osaka, Japan. He received his Bachelor's degree (1998) in coordination chemistry from Kanazawa University, and his Master's degree (2000) in physical chemistry for life science from Osaka University. He joined Mitsui Chemicals Inc. in 2000 as a researcher. His research interests include coordination chemistry, organometallic chemistry, and development of olefin polymerization catalyst systems. He is a recipient of the Chemical Society of Japan Award for Young Chemists in Technical Development for 2002.

Terunori Fujita was born in November 1957 in Ehime, Japan. He received his B. S. and M. S. degrees in chemistry, natural product synthesis, from Hokkaido University, working with Professors Takeshi Matsumoto and Haruhisa Shirahama. He obtained his Ph.D. degree in organic chemistry, anion coordination chemistry, from l'Université Louis Pasteur de Strasbourg, France, in 1988 with Professor Jean-Marie Lehn.

He joined Mitsui Petrochemical Industries, Ltd. (now Mitsui Chemicals, Inc.) in 1982, where he is now one of the four research fellows. Most recently, he has been working on the development of highly-active olefin polymerization catalysts and their applications to the preparation of polymers with new or enhanced material properties. $\mathrm{He}$ is a recipient of the Catalysis Society of Japan Award for Young Researchers for 2001 and the JLPO Award (Italy) in 2002. 